\title{
A Comparative Study of Protective Schemes for Shield Tunneling Adjacent to Pile Groups
}

\author{
Penglin Li, ${ }^{1,2}$ Yuquan Lu, ${ }^{1}$ Jinxing Lai $\left(\mathbb{D},{ }^{1}\right.$ Houquan Liu, ${ }^{3}$ and Ke Wang $\mathbb{D}{ }^{4,5}$ \\ ${ }^{1}$ School of Highway, Chang'an University, Xi'an 710064, China \\ ${ }^{2}$ Research and Development Department, China Harbour Engineering Co., Ltd., Beijing 100027, China \\ ${ }^{3}$ China Railway Siyuan Survey and Design Group Co., Ltd., Wuhan 430063, China \\ ${ }^{4}$ State Key Laboratory of Rail Transit Engineering Informatization, \\ China Railway First Survey and Design Institute Group Co., Ltd., Xi'an 710043, China \\ ${ }^{5}$ Institute of Geotechnical Engineering, Xi'an University of Technology, Xi'an 710048, China
}

Correspondence should be addressed to Jinxing Lai; laijinxing@chd.edu.cn and Ke Wang; 372836091@qq.com

Received 4 August 2019; Revised 5 October 2019; Accepted 23 November 2019; Published 21 January 2020

Academic Editor: Giovanni Garcea

Copyright (c) 2020 Penglin Li et al. This is an open access article distributed under the Creative Commons Attribution License, which permits unrestricted use, distribution, and reproduction in any medium, provided the original work is properly cited.

Shield tunneling adjacent to pile groups is always an unavoidable problem in urban metro construction. A case was found in the project of Tianjin Metro Line 7, where a shield tunnel would be constructed near the existing pile groups of Shiyou Bridge. The whole shield tunnel is close to pile groups, and the minimum distance is only $0.8 \mathrm{~m}$. Therefore, four kinds of protective schemes are proposed in this paper. It is vital to select an appropriate protective scheme to guarantee the safety during the tunnel construction. In this study, the main mechanical characteristic and physical parameters of site soil were obtained through laboratory tests. Besides, the three-dimensional finite element method was carried out to compare and analyze the effectiveness of the protective schemes in mitigating the effects of tunneling on adjacent pile groups. The results show that the deep-hole grouting scheme has better control effect on the lateral deformation and bending moment of piles, while the pile foundation underpinning scheme has better effectiveness on reducing the settlement of bridge structure and ground deformation. Finally, the deep-hole grouting reinforcement scheme will be adopted to ensure the shield passing through the pile groups smoothly.

\section{Introduction}

With the development of urban underground space, there are more and more cases of shield tunneling underneath or adjacent to existing pile foundations of buildings. Tunnel construction inevitably redistributes the initial stress of soil, causing surface subsidence, inclination, curvature change, horizontal dislocation, and discontinuous deformation, which may affect the nearby pile foundations, thus bringing potential safety hazards to the building structures [1-7]. The effect of tunneling on existing pile foundations has caused great trouble to the design and construction of urban subway, and many researchers have studied it by numerical and analytical methods [8-16]. Besides, a number of centrifuge model tests [17-23] and field observations [24-31] have been carried out to investigate the influence of tunneling on ground and nearby pile foundations.
Underground pile foundations are dense in cities with crowded buildings. If the distance between pile foundation and shield is too close, tunneling may cause uneven settlement, structural deformation, and cracks in buildings [32-37]. To ensure the smooth advance of shield and the safety of adjacent pile foundations, it is necessary to take some protective measures [38-50]. Bilotta and Russo [42] adopted a simple row of piles to prevent buildings from being damaged by tunneling. Through three-dimensional finite element analysis and centrifugal test, it was concluded that settlement reduction is significant for very small spacing, and large spacing piles are also helpful in reduction of average horizontal strain. Bai et al. [43] adopted three protection techniques in the complicated construction processes: an underground cutoff wall was used to separate the buildings and tunnel when their distance is less than $5 \mathrm{~m}$; the grouting reinforcement technique was adopted when the 
minimum distance is between $5 \mathrm{~m}$ and $10 \mathrm{~m}$; and if the minimum distance is larger than $10 \mathrm{~m}$, the optimized construction parameters were selected to reduce the influence induced by the excavation. Fu et al. [45] evaluated the effectiveness of underground jet-grouted partition wall in mitigating the effects of shield-tunnel construction on existing piled structures through numerical analysis and field monitoring. Their results indicated that the presence of partition wall can relieve the existing piles from suffering from differential displacement, thereby improving the mechanical performance of pile-pier interaction. Wang et al. [46] expanded and strengthened the raft foundation of Fengqi Bridge and improved the composite ground. They analyzed monitoring data before and after the shield body crossing the bridge and found that these enhancements can effectively decrease bridge settlement during tunneling and improve mechanical conditions of bridge structures.

However, in such a difficult engineering background, the previous researches on this aspect are still not rich enough. With the process of urbanization, there are more projects of tunneling underneath or adjacent to pile foundations, and the spacing between pile foundation and shield is getting smaller. These researches mainly concentrate on conventional pile foundation, while little research was done to study the deep foundations of overpasses or viaducts, especially when the tunnel is so close to the pile foundation.

In the project of Tianjin Metro Line 7, the tunnel was constructed near the existing pile groups of Shiyou Bridge. In order to ensure the smooth advance of shield and the safety of adjacent pile groups, this paper makes a comparative study of the effects of protective schemes on reducing the influence of tunnel construction on pile foundations. The outline of the paper is as follows: Section 2 presents the overview of Tianjin Metro Line 7 project and describes the site geology. The main mechanical characteristic and physical parameters of site soil were obtained through laboratory tests. In Section 3, the method of establishing the three-dimensional numerical model of tunnel and bridge and the constitutive model and calculation parameters are described. Section 4 illustrates the four protective schemes and their applications. In Section 5, by performing a series of three-dimensional finite element analyses, the stress and deformation of pile groups affect by tunneling were studied. The numerical results of three cases were compared to evaluate the effectiveness of the protective schemes in mitigating the effects of tunnel construction on adjacent pile groups. And a scheme suitable for tunnel construction was proposed. Finally, conclusions and sum-up of the paper are presented.

\section{Engineering Background}

2.1. Project Overview. As shown in Figure 1, Tianjin Metro Line 7 is located in Tianjin, China. The metro line is $26.5 \mathrm{~km}$ in total length, which was constructed as twin-bored singletrack tunnels with 21 stations. According to the design documents, the interval tunnel from Lijiang Road station to Tumor Hospital station would have to pass the adjacent pile groups of Shiyou Bridge. The twin tunnels with an outer diameter of $6.0 \mathrm{~m}$ having a lining thickness of $0.3 \mathrm{~m}$ were excavated by using two earth pressure balance (EPB) shieldtunnel boring machines. The overburden above the tunnel varies from 17.3 to $19.1 \mathrm{~m}$. The Shiyou Bridge is a pier column bridge, and the deck structure is a concrete continuous box girder with a width of $7 \mathrm{~m}$. Under each pile cap, there are four bored piles with a diameter of $1 \mathrm{~m}$, a length of $40 \mathrm{~m}$, and a spacing of $2.6 \mathrm{~m}$.

The spatial position relation of the pile groups and the shield tunnel can be found in Figure 2. The study area is between the right line design mileage YDK21 + 134.382 and the left line design mileage ZDK21 + 201.596. The tunnel is very close to the pile groups, and the minimum horizontal distance from the left line to the pile is $0.8 \mathrm{~m}$. The distance between the right line and adjacent piles is $1.18 \mathrm{~m}, 1.20 \mathrm{~m}$, and $1.64 \mathrm{~m}$, respectively.

2.2. Site Condition. The construction site is situated on the marine-alluvial coastal plain. As shown in Figure 3, the stratum from ground surface to the depth of $60 \mathrm{~m}$ is divided into 7 layers in terms of soil characteristics, i.e., miscellaneous fill layer, brown to brown grey silty clay layer (CL1 ), brown grey silt layer (ML), gray silty clay layer (CL-2), black grey to gray silty clay layer (CL-3), grayish yellow silty clay layer (CL-4), and yellowish brown silty clay layer (CL5). The shield machine mainly crosses through the gray silty clay layer (CL-2) when arriving at the Shiyou Bridge. The groundwater in this area is Quaternary pore water which can be divided into phreatic water and confined water. The depth of phreatic water is $2.5 \mathrm{~m}-3.8 \mathrm{~m}$, and the confined water mainly exists in the silt layer and silty sand layer which is below the tunnel. Therefore, the influence of underground water is not considered during shield construction.

2.3. Mechanical Tests on Site Soil. According to the different soil layers, the undisturbed soil with seven depth points was drilled in the engineering site to carry out laboratory triaxial compression tests. At least 6 test soil samples were prepared for each layer of soil obtained at the site. And consolidatedundrained shear tests were conducted on samples under varying confining pressure between $100 \mathrm{kPa}$ and $350 \mathrm{kPa}$ with a pressure increment of $50 \mathrm{kPa}$. Figure 4 shows the stress-strain curves of the fifth layer soil under different confining pressures. From the test curves, it can be seen that with the increase of shear strain, the shear stress increases gradually, and the shear stress increases faster in the initial stage. When the shear strain increases to a certain extent, the increasing trend of shear stress slows down and gradually reaches its peak value. The strength parameters of the samples are shown in Table 1.

The soil samples were loaded repeatedly during the test. Figure 5 shows the stress-strain curves of the fourth layer soil under repeated loading, which can conclude that soil shows the softening characteristics under small confining pressure, but with the increase of the confining pressure, soil exhibits the hardening characteristics. The peak strengths of the soil samples increase as the confining pressure increase. The depth of shield tunneling is about $20 \mathrm{~m}$, and the influence 


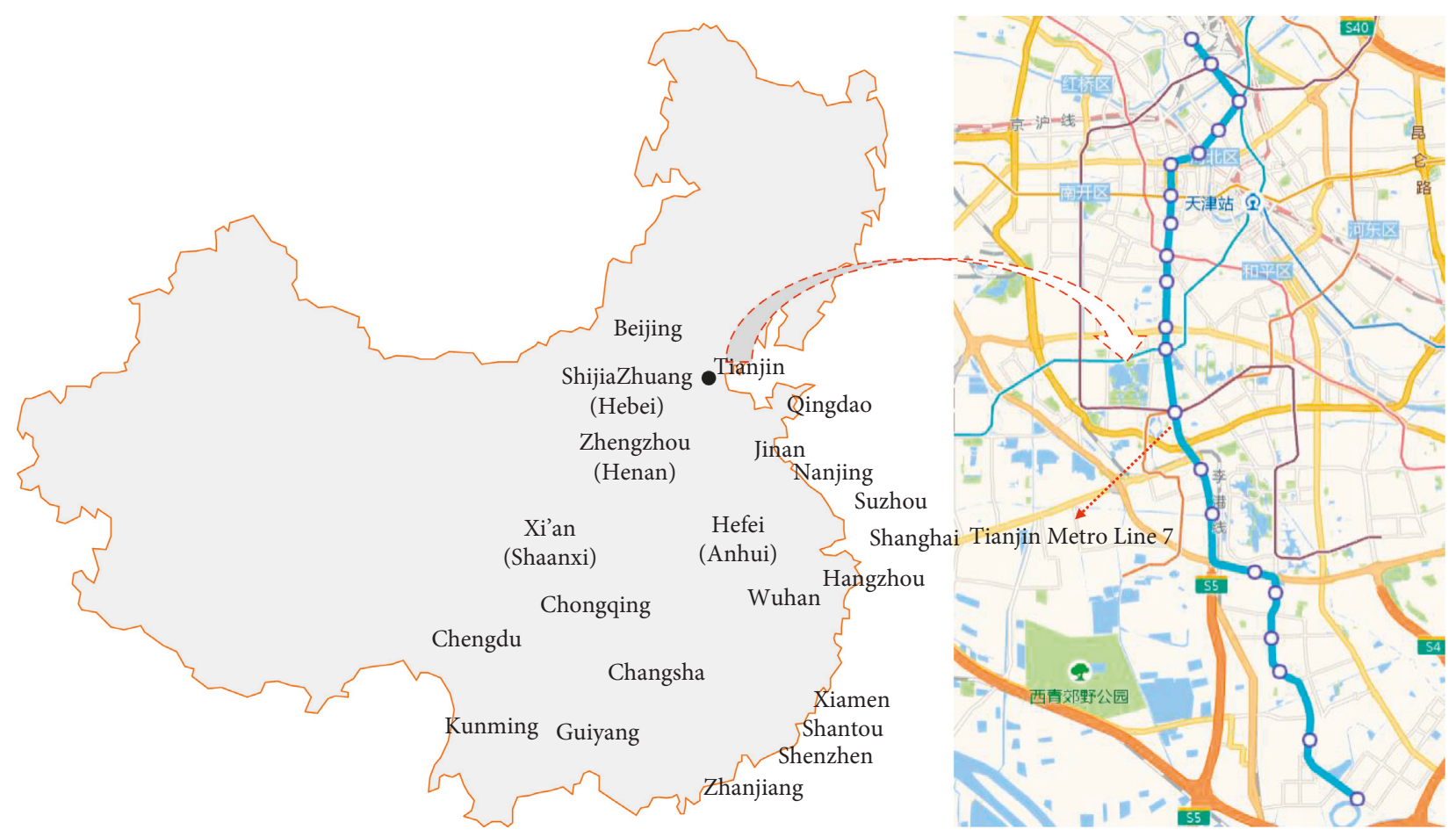

Figure 1: The location of Tianjin Metro Line 7.

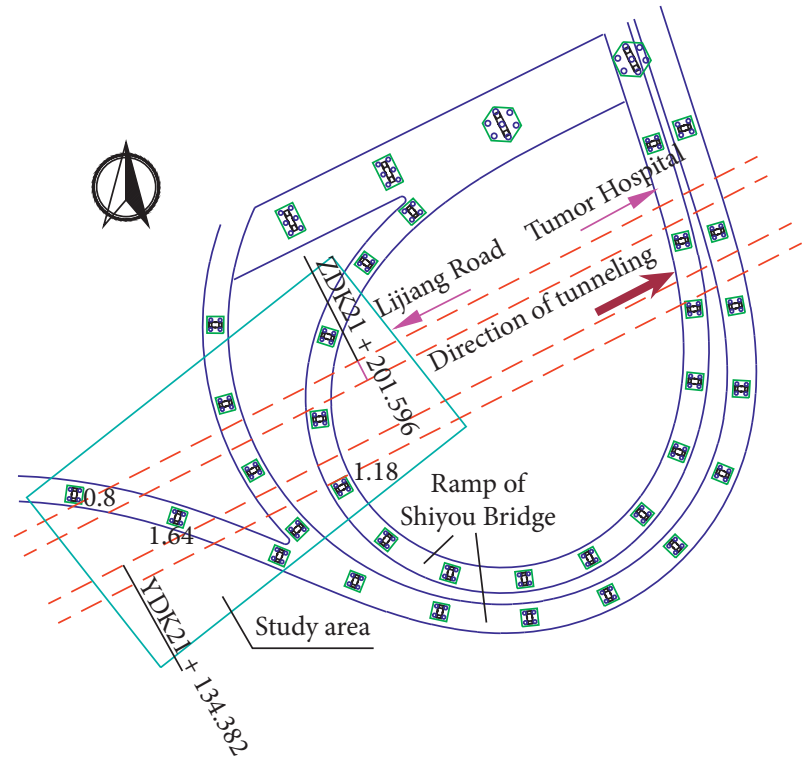

FIgURE 2: Location of pile groups and shield tunnel (unit: m).

area of shield tunneling on pile foundation is mainly concentrated in the fourth layer of soil. Therefore, the hardening characteristics of soil should be taken into account in the constitutive model.

\section{Numerical Simulation}

3.1. Numerical Model. According to the overview of Tianjin Metro Line 7 project, there are many piles along the construction line. The finite element software Midas GTS was

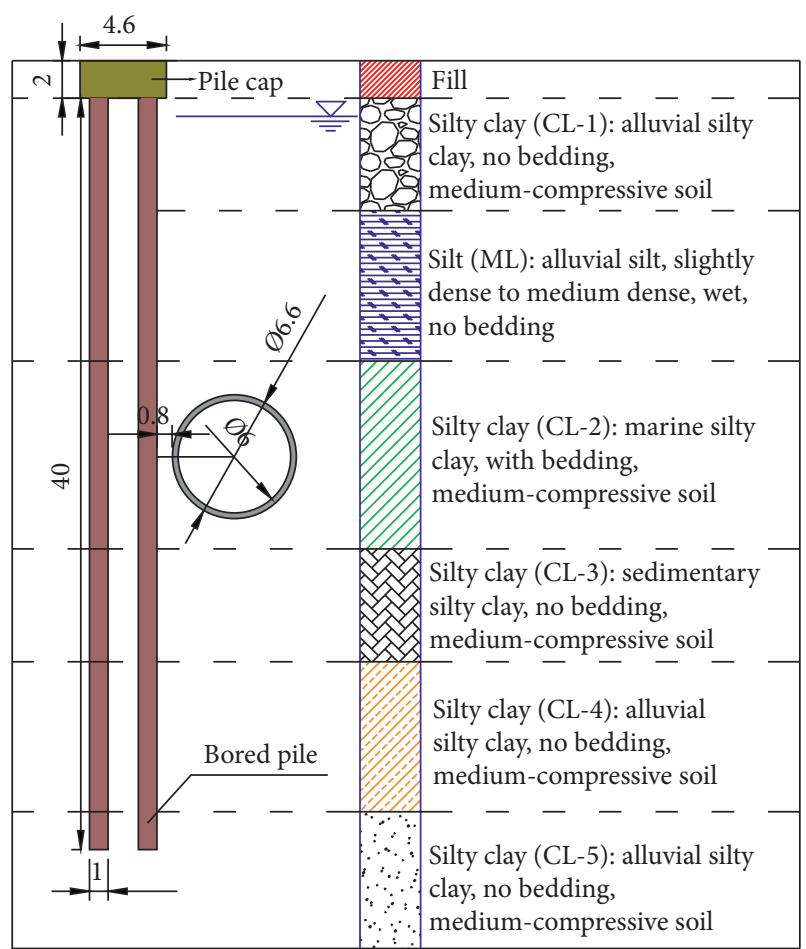

FIGURE 3: Engineering geological profile (unit: $\mathrm{m}$ ).

employed for numerical simulation. Considering the influence of boundary effects on the accuracy of the numerical results, the area with the most risk of construction was selected to build a 3D finite element model to analyze the influence of tunnel construction on 12 adjacent pile groups. 


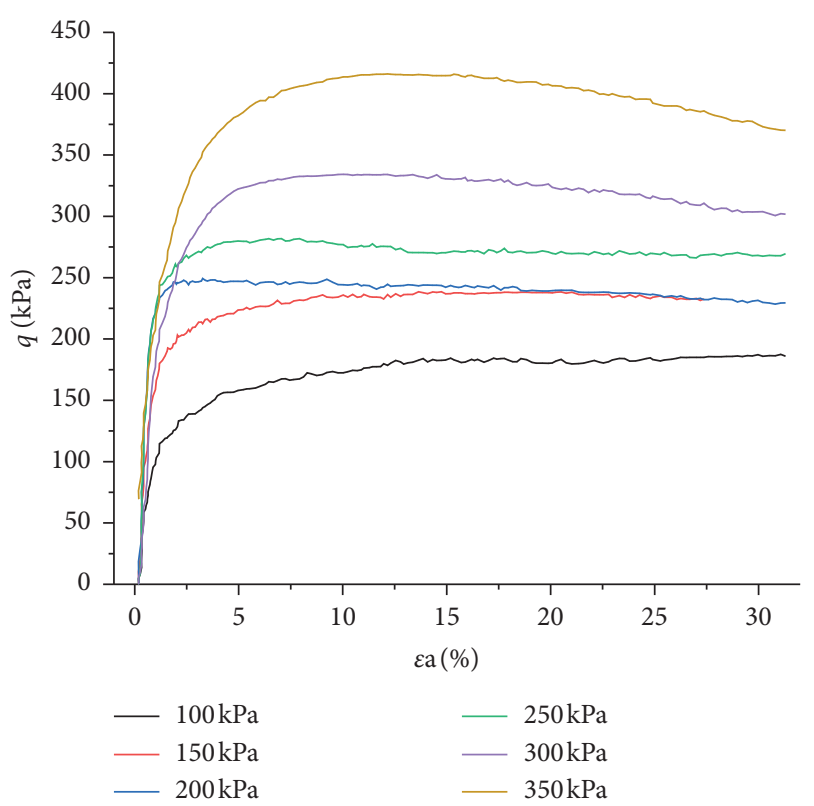

Figure 4: Stress-strain curves of silty clay (CL-3).

A perspective view of the numerical model is shown in Figure 6. The mesh applied in this model consisted of 37,254 nodes and 73,193 elements. Dimensions of the soil body were selected to be $120 \mathrm{~m}$ (length) $\times 120 \mathrm{~m}$ (width) $\times 65 \mathrm{~m}$ (depth). The soil mass, four-pile caps, and tunnel linings were simulated using tetrahedron elements. The shield and bridge deck were simulated as plate elements. And the beam elements were used in piles. In this model, soil mass and piles were considered as continuum solids. The shield machine was simplified as a continuum shell. Tunnel linings were simulated as continuum solids without taking into account the joints. To simulate the boundary conditions, displacement of the four vertical boundaries was set to be zero in the horizontal direction and left free to settle vertically. Furthermore, the bottom boundary was fixed, and the top boundary was free.

3.2. Constitutive Model and Calculation Parameters. The accuracy of numerical simulation results is mainly affected by two factors: the constitutive model and calculation parameters. Through the triaxial test, the main characteristic of the stress-strain curve of Tianjin soft soil studied in this paper is that it shows hardening behaviour with the increase of confining pressure. The applicability of various constitutive model geomaterials has been studied for typical Tianjin soft soil. The Mohr-Coulomb and Drucker-Prague constitutive models commonly used in numerical simulation do not reflect the hardening characteristic well. Since it is assumed that the shear strength of soft soil does not change with time, the modified Cambridge model is not adopted. Finally, the constitutive behaviour of soft soil is modelled with a modified Mohr-Coulomb model which can not only make up for the deficiency of the Mohr-Coulomb model but also simulate the hardening behaviour of soft soil. The modified Mohr-Coulomb constitutive model takes into account the correlation between soil stiffness and stress state and adopts double hardening modes in the shear direction and compression direction. Its yield criterion includes the nonlinear elastic part and the plastic part. In addition, compared with the Mohr-Coulomb model, the modified Mohr-Coulomb model is computationally more efficient.

The soil parameters adopted in the numerical simulation are mainly determined from correlating local investigated data and laboratory tests (Table 2). The piles, tunnel linings, shield body, and grout are treated as linear isotropic elastic materials. C50 (50 MPa cube strength) concrete was used in the tunnel linings, and C25 (25 MPa cube strength) concrete was used in the piles. Table 3 presents the parameters of bridge structure and materials.

In numerical calculation, the mechanical model of soil mass is highly nonlinear, and the soil-pile interface is discontinuous. These two factors lead to the nonconvergence problem in the calculation process. The piles studied in this paper belong to friction piles, whose bearing capacity mainly depends on the side friction of piles. Under the action of large extrusion force in shield construction, the pile-soil interface will produce dislocation slip. Therefore, the interface elements were used to simulate pile-soil interaction at the side and base of the piles. The interfaces are governed by shear stiffness $K_{\mathrm{t}}$, normal stiffness $K_{\mathrm{n}}$, and final shear force. The final shear force is the ultimate shear strength of the soil around the piles, which is obtained from laboratory tests. Zhu [51] adopted the field test to study the pile-soil contact relationship in silty clay. The results show that the shear stiffness increases with the increase of normal pressure of the pile body, and the value of $K_{\mathrm{t}}$ is between $35.7 \mathrm{MPa} / \mathrm{m}$ and $102 \mathrm{MPa} / \mathrm{m}$. Dong [52] studied the parameters of pile-soil interface through the field test. The results show that the $K_{\mathrm{t}}$ value is between $1 / 10$ and $1 / 100$ of the $K_{n}$ value, and when the $K_{\mathrm{t}}$ value exceeds the order of $0.1 \mathrm{MPa} / \mathrm{m}$, the parameters of pile-soil interface are less affected, which is close to the results calculated by software. Based on the previous studies and continuous attempts in the software, the parameters of pile-soil interface used in the analyses are shown in Table 4.

3.3. Numerical Procedure. A typical "step-by-step" approach was adopted to simulate the shield construction process $[13,53,54]$. The numerical modelling consisted of three key steps, i.e., shield tunneling, lining assembly, and shield tail grouting. As shown in Figure 7, the following modelling sequence is followed:

(1) This paper only considers the influence of shield tunneling on pile groups. Thus, the first step was to model the wished-in-place pile, and the axial load determined from the pile loading test was applied to the pile head. Then, the displacements were reset to zero.

(2) Uniformly distributed pressures were applied to the soil meshes on the excavation face to simulate the face support pressures during shield tunneling. The corresponding soil elements were removed from the model by the "element death" technique. The shield 
TABLE 1: Shear strength parameters of triaxial tests.

\begin{tabular}{lcccc}
\hline Soil sample number & Stratum (Figure 3) & Depth $(\mathrm{m})$ & Cohesion $(\mathrm{kPa})$ & Friction angle $\left(^{\circ}\right)$ \\
\hline 1 & Fill & 1.8 & 5 & 10.1 \\
2 & Silty clay (CL-1) & 5.6 & 14.4 & 15.9 \\
3 & Silt (ML) & 13.2 & 15.9 & 28.3 \\
4 & Silty clay (CL-2) & 21.2 & 18.7 & 20.9 \\
5 & Silty clay (CL-3) & 28.9 & 23.6 & 14.5 \\
6 & Silty clay (CL-4) & 34.5 & 24.4 & 19.4 \\
7 & Silty clay (CL-5) & 42.6 & 20.1 \\
\hline
\end{tabular}

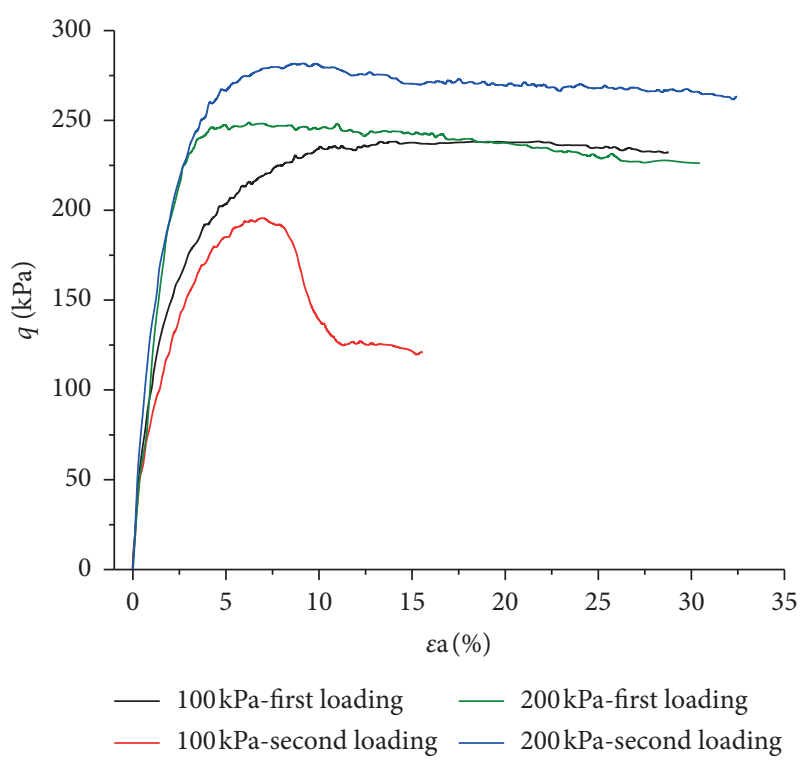

FIGURE 5: Stress-strain curves of silty clay (CL-2) under repeated loading.

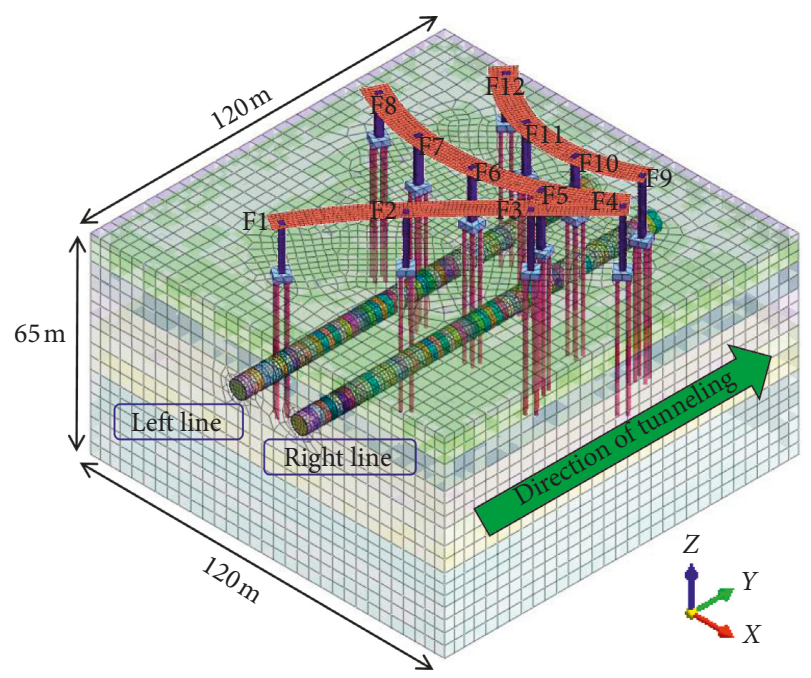

Figure 6: Three-dimensional finite element model.

machine was driven forward for 7 slices (each slice is of one ring width of $2 \mathrm{~m}$ ), and shield elements were activated at the same time.

(3) The first slice of lining was activated after the excavation. Jacking forces were applied in front of the shield to simulate the jacking process.
(4) At the shield tail, the grouting layer was activated in the gap between the lining and the excavated soil. And radial pressures were applied at the soil periphery to simulate grouting pressures.

In the sequential excavation, at each construction step one slice of soil elements was deactivated in the model and the corresponding elements were activated or deactivated. During the construction simulation, there are 120 steps (one slice at each excavation step) in total; the left line was advancing first, and then the right line was excavated.

\section{Selection of Protective Schemes}

Shield tunneling will cause great disturbance to the surrounding soil and will have a great impact on adjacent pile groups, which will cause a certain degree of flexural deformation of pile foundation, further affecting the bearing capacity of pile foundation. Therefore, in order to ensure the safety of pile structure, it is essential to take some measures, among which shield construction parameters should be optimized first. According to previous experience and references [55-58], the disturbance of shield tunneling to soils can be reduced by controlling the face support pressure $(200 \mathrm{kPa})$, synchronous grouting pressure $(250 \mathrm{kPa})$, and jacking force $(3500 \mathrm{kPa})$. In addition, the effective schemes to substantially reduce the influence caused by tunneling are reinforcement of soil or adjacent pile itself, isolation, and pile foundation underpinning. This paper will select suitable schemes through comprehensive consideration.

4.1. Deep-Hole Grouting Reinforcement Scheme. As shown in Figure $8(\mathrm{a})$, the implementation process of the deep-hole grouting scheme is to inject of cement-sodium silicate slurry evenly in half or full section of the shield tunnel. The injected slurry is squeezed and infiltrated into the surrounding soil of the existing tunnel, which changes the physical and mechanical parameters of soil and the seepage path of groundwater. As the overall strength of soil increases, the extrusion force produced by shield tunneling is more consumed in the reinforced soil, thus reducing the influence of shield construction on pile group foundation. The grouting scheme has the advantages of low cost, low noise, and small vibration. Previous studies show that the deephole grouting reinforcement scheme can effectively reduce the ground settlement. 
TABLE 2: Physical and mechanical properties of soil.

\begin{tabular}{lccccccccc}
\hline Stratum (Figure 3) & Thickness $(\mathrm{m})$ & $r\left(\mathrm{kN} / \mathrm{m}^{3}\right)$ & $e$ & $\mu$ & $I_{\mathrm{P}}$ & $I_{\mathrm{L}}$ & $E s_{1-2}(\mathrm{MPa})$ & $c(\mathrm{kPa})$ & $\varphi\left(^{\circ}\right)$ \\
\hline Fill & 2 & 19.7 & 0.84 & 0.31 & 13.7 & 0.41 & 4.5 & 5 \\
Silty clay (CL-1) & 6 & 19.3 & 0.82 & 0.3 & 14.6 & 0.69 & 5.6 & 10.1 \\
Silt (ML) & 8 & 19.7 & 0.72 & 0.25 & 9.6 & 0.47 & 13.7 & 9.6 \\
Silty clay (CL-2) & 11 & 18.8 & 0.89 & 0.25 & 14.2 & 0.84 & 4.9 & 28.3 \\
Silty clay (CL-3) & 5 & 20.7 & 0.57 & 0.25 & 12.5 & 0.29 & 7.0 & 15.9 \\
Silty clay (CL-4) & 8 & 19.8 & 0.73 & 0.32 & 13.9 & 0.54 & 6.8 & 20.9 \\
Silty clay (CL-5) & 25 & 20.0 & 0.69 & 0.3 & 13.9 & 0.44 & 7.1 & 14.5 \\
\hline
\end{tabular}

$r$ : unit weight; $e$ : void ratio; $\mu$ : Poisson's ratio; $I_{\mathrm{P}}$ : plasticity index; $I_{\mathrm{L}}$ : liquid index; $E s_{1-2}$ : compressive modulus; $c$ : cohesion; $\varphi$ : friction angle.

TABLE 3: Calculation parameters of bridge structure and materials.

\begin{tabular}{lccc}
\hline Materials & Elastic modulus $(\mathrm{kPa})$ & Poisson's ratio & $\begin{array}{c}\text { Density } \\
\left(\mathrm{kN} / \mathrm{m}^{3}\right)\end{array}$ \\
\hline Deck & $2.7 \times 10^{7}$ & 0.22 & 23 \\
Pier & $4.6 \times 10^{7}$ & 0.2 & 24 \\
Cap & $5.7 \times 10^{7}$ & 0.18 & 25 \\
Pile foundation & $2 \times 10^{6}$ & 0.3 & 21 \\
Lining & $3.45 \times 10^{7}$ & 0.3 & 24 \\
Shield & $2.1 \times 10^{8}$ & 0.2 & 78 \\
Grouting & $4 \times 10^{5}$ & 0.3 & 22.5 \\
\hline
\end{tabular}

TABLE 4: Soil mechanical properties.

\begin{tabular}{lccc}
\hline $\begin{array}{l}\text { Stratum } \\
\text { (Figure 3) }\end{array}$ & $\begin{array}{c}K_{\mathrm{n}} \\
(\mathrm{MPa} / \mathrm{m})\end{array}$ & $\begin{array}{c}K_{\mathrm{t}} \\
(\mathrm{MPa} / \mathrm{m})\end{array}$ & $\begin{array}{c}\text { Side friction of pile } \\
(\mathrm{kPa})\end{array}$ \\
\hline Silty clay (CL-1) & 400 & 40 & 18.29 \\
Silt (ML) & 550 & 55 & 41.85 \\
Silty clay (CL-2) & 650 & 65 & 43.65 \\
Silty clay (CL-3) & 750 & 75 & 46.02 \\
Silty clay (CL-4) & 900 & 90 & 53.97 \\
Silty clay (CL-5) & 1000 & 100 & 58.62 \\
\hline
\end{tabular}

4.2. Grouting Reinforcement Scheme for Piles. Similar to the deep-hole grouting scheme, the existing pile group foundation is reinforced by grouting around the piles (Figure 8(b)). Grouting improves the mechanical properties of soil around piles, forms pile-side soil, and pile group foundation as a whole with high strength. Moreover, the mechanical properties of pile-soil interface are improved after grouting. The skin friction of pile is brought into full play, and the bearing capacity of pile foundation is also improved. However, due to the pile foundation studied in this paper is as long as $40 \mathrm{~m}$, the grouting reinforcement scheme around the pile foundation is difficult to construct. So it is not recommended to adopt this scheme.

4.3. Isolation Piles and Partition Wall Schemes. Figure 9 presents the schemes of isolation piles and partition wall. Shield tunneling will produce a large extrusion force during the construction. The extrusion force is transmitted to the pile foundation by surrounding soil as a medium, which has a great impact on the pile foundation. In order to minimize the transmission of this force, isolation piles or partition wall is installed between pile foundation and tunnel. The rigidity of isolation structure is used to block the extrusion force in the construction process so as to control the deformation of the surrounding soil and protect the nearby pile group foundation. Previous studies show that this scheme can relieve the existing piles from suffering from differential displacement, thereby improving the mechanical performance of piles. However, the implementation of the isolation scheme is greatly affected by construction site, and the distance between pile foundation and shield tunnel is also limited. When the tunnel is too close to the piles, the construction of isolation structure will cause settlement of the soil and will also have a certain impact on the pile foundation. There are many pile groups along the construction line, and the minimum distance from the pile to the tunnel side is $0.8 \mathrm{~m}$. Therefore, it is impractical to adopt the isolation schemes.

4.4. Pile Foundation Underpinning Scheme. Shield tunneling has a greater influence on the bearing capacity of pile foundation, thus affecting the safety of bridge structure. Figure 10(a) shows the active pile underpinning technology. By establishing new pile foundation, the load acting on the existing pile foundation can be transferred to the underpinning pile through underpinning beams. During shield construction, most of the external load will be loaded on the new pile foundation, resulting in settlement of the new pile foundation. The passive pile underpinning technology is to enlarge the structure of the pile caps and form a new pile group bearing system with new piles and existing piles, as presented in Figure 10(b). The new pile foundations share part of the upper load, so as to improve the bearing capacity of the existing pile foundation. The passive pile underpinning scheme can be applied to the project studied in this paper.

\section{Comparative Analysis of Protective Schemes}

According to the actual conditions of the construction site, two suitable protective schemes were selected: the deep-hole grouting reinforcement scheme and pile foundation underpinning scheme. And two different finite element models (Figure 11) were generated to further select the better scheme of the two protective schemes. In the simulation of the deep-hole grouting scheme, the grouting depth is $0.5 \mathrm{~m}$, and the whole section is grouted before shield excavation. Each step of shield propulsion is one ring, and grouting is ahead of one step of shield excavation. In the scheme of pile foundation underpinning, a total of four caps were enlarged 


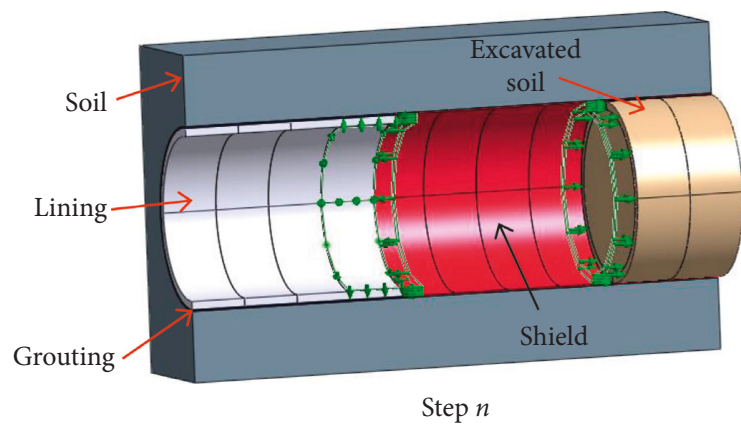

(a)

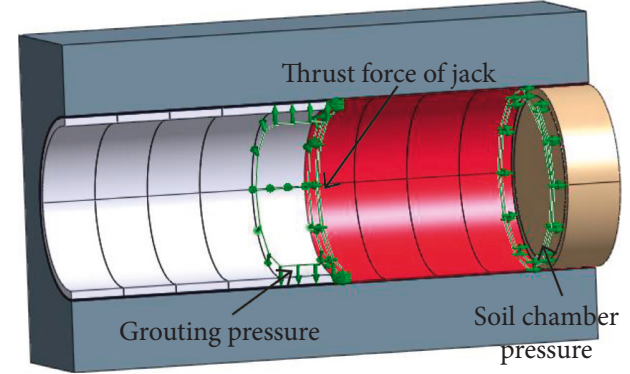

Step $n+1$

(b)

FIgURE 7: Finite element simulation of shield tunneling.

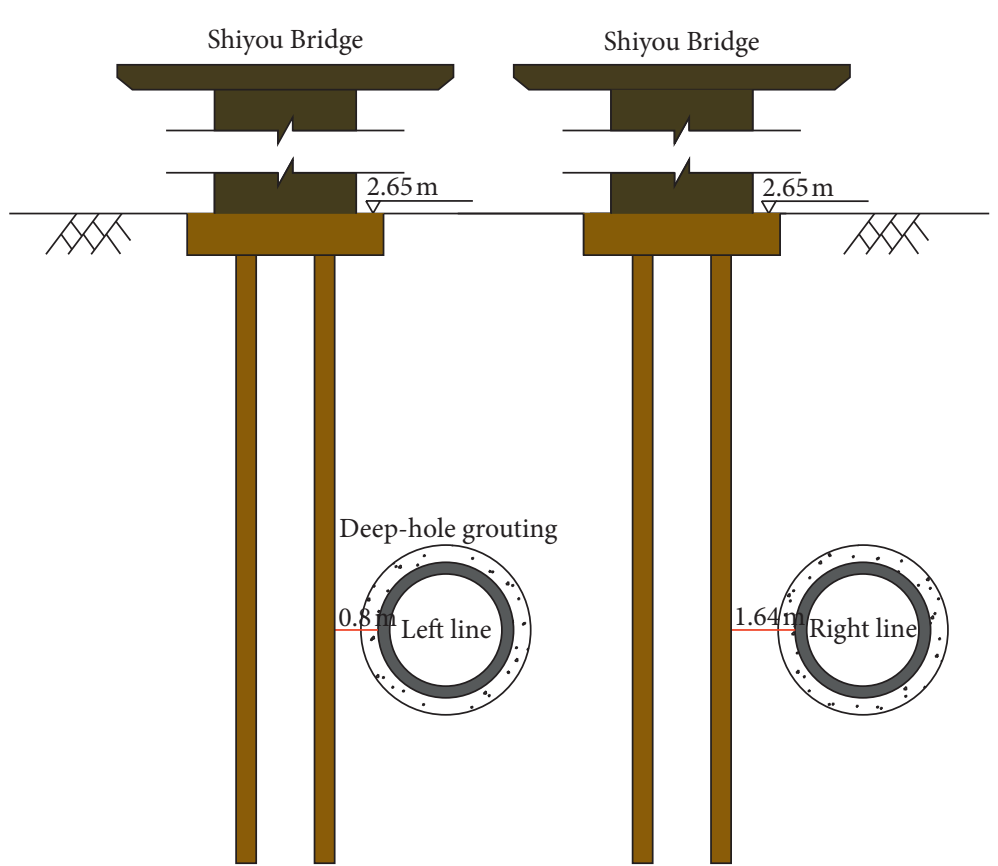

(a)

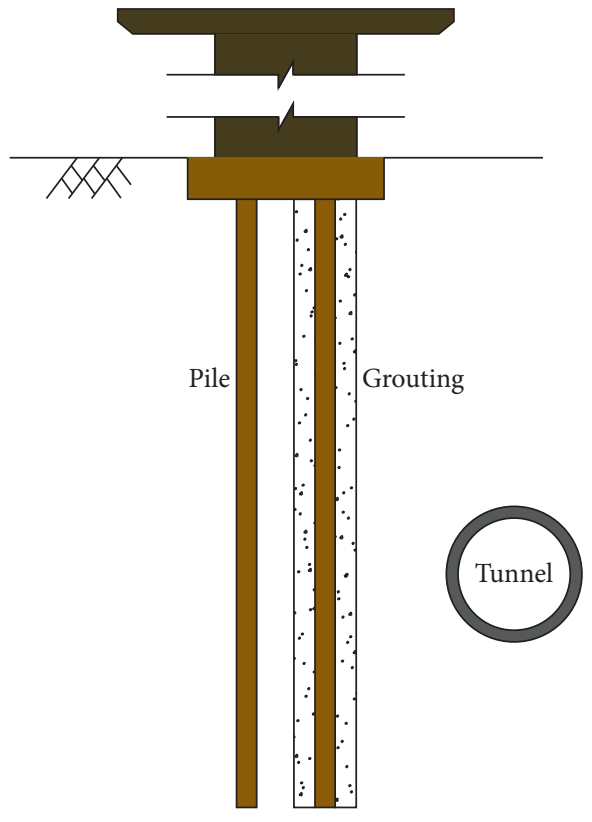

(b)

FIGURE 8: Grouting reinforcement scheme: (a) deep-hole grouting; (b) grouting for pile.

and eight pile foundations were added before tunnel excavation, as shown in Figure 11(b). In the calculation results, vertical displacement of bridge, settlement of ground surface, lateral deformation of piles, and bending moment of piles were selected as reference values to compare and analyze the mitigating effect of the two schemes.

5.1. Vertical Displacement of Bridge. Figure 12 compares the calculation result of vertical displacement of the whole model after shield tunneling for three schemes. It is shown that the settlement of bridge caused by tunnel construction is obviously reduced after adopting protective schemes. Among them, the maximum settlement without protection is about $8.0 \mathrm{~mm}$. In the schemes of pile foundation underpinning and deep-hole grouting, the maximum settlement is about $2.9 \mathrm{~mm}$ and $4.4 \mathrm{~mm}$, respectively, which reduced approximately $63.2 \%$ and $45.4 \%$. Such reductions infer that the deep-hole grouting scheme has better effect on reducing the overall settlement. From the calculation result, it can be seen that the caps and the corresponding superstructure have experienced almost the same settlement due to the use of concrete elastic materials. Furthermore, it can be found from Figure 12(c) that after tunnel excavation, the bridge structure (including bridge deck, piers, and caps) has a large settlement, especially the settlement of superstructure of pile group foundation (F2) is the largest (about $7.8 \mathrm{~mm}$ ), which shows that shield tunneling indeed has a great impact on the stability of bridge structure. In contrast with Figure 12(a), it is clear that the settlement of the whole bridge is significantly reduced after deep-hole grouting, and the settlement distribution is similar to that of the unreinforced scheme. This is due to the grouting improves the strength of surrounding soil, thus reducing the influence of 


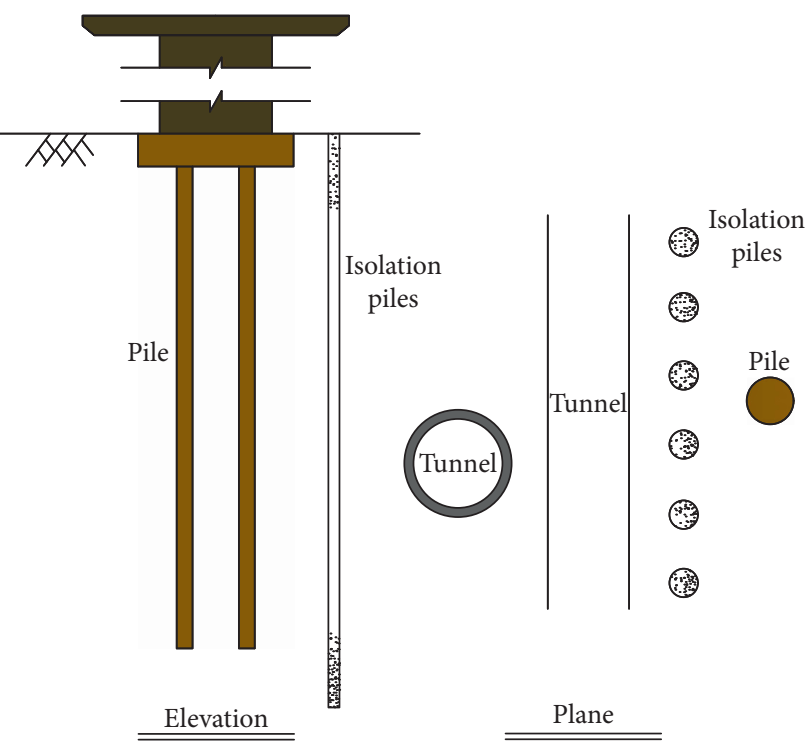

(a)

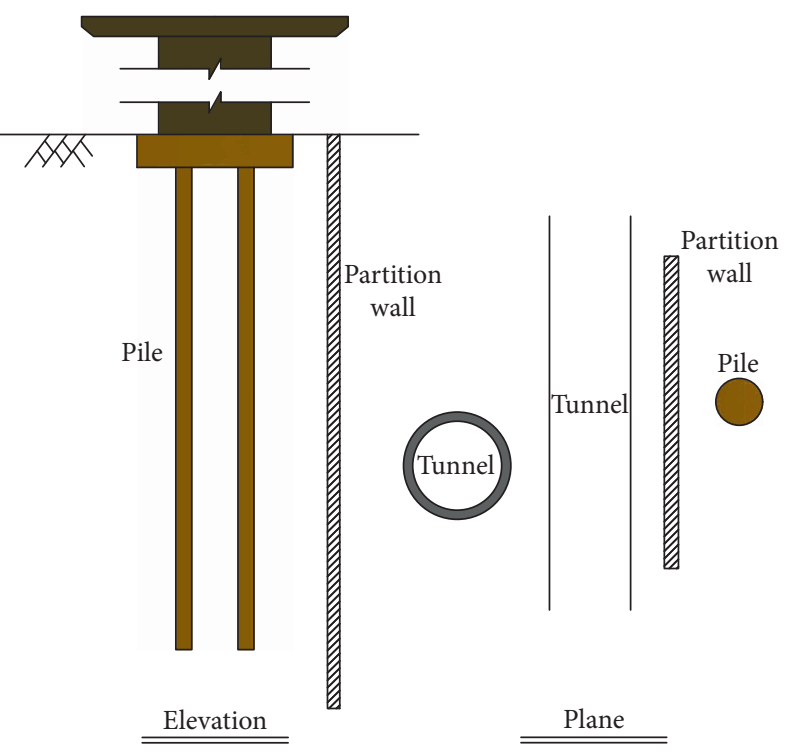

(b)

FIGURE 9: Isolation scheme: (a) isolation piles; (b) partition wall.

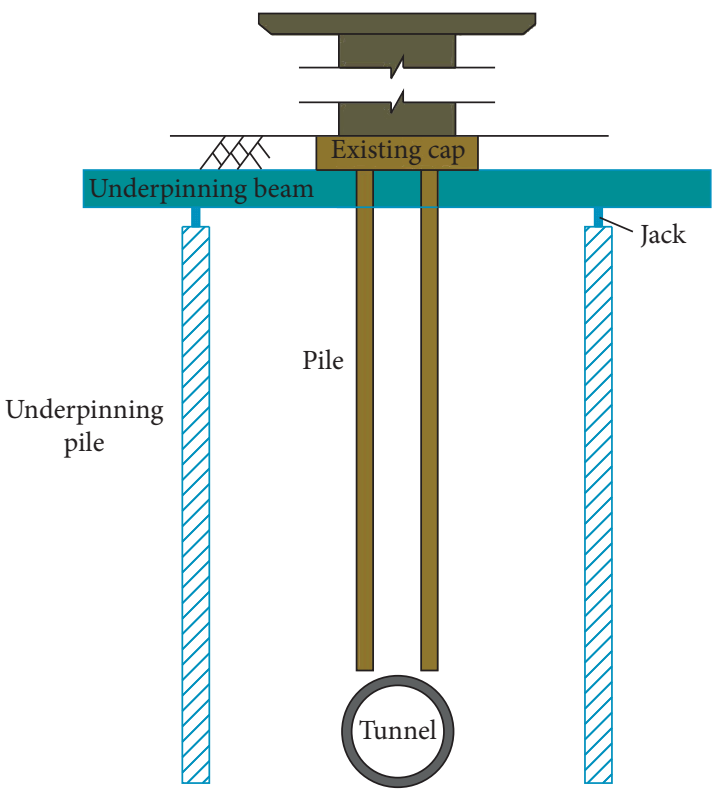

(a)

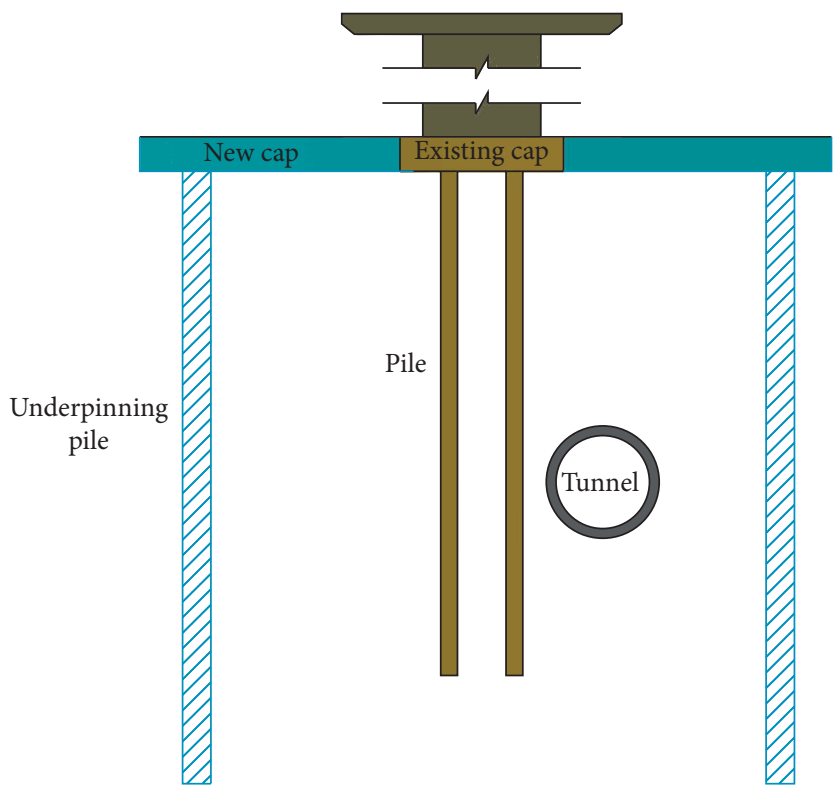

(b)

FIGURE 10: Pile foundation underpinning scheme: (a) active underpinning; (b) passive underpinning.

tunnel excavation on the whole bridge. Compared with the pile foundation underpinning scheme in Figure 12(b), it is obvious that the overall settlement of bridge as well as the settlement difference of adjacent piers is the smallest in three schemes. After the reinforcement of pile group foundations of F1, F2, F11, and F12, the settlement of the corresponding superstructure decreases significantly, while the maximum settlement occurs on the superstructures of F5 and F6. The underpinning pile foundation is used to reinforce the bridge structure, and when the tunnel is excavated, the load is transferred to the underpinned piles to replace the adjacent piles to bear the load, which makes the structure more stable in force and more uniform in settlement. The results show that the bridge is safe at the end of tunnel excavation. The deep-hole grouting scheme reduces the settlement of the whole bridge structure, and the settlement distribution of the bridge is similar to that of the unreinforced scheme. The pile foundation underpinning scheme has better effect on the settlement control of bridge structure. The settlement distribution of bridge structure has changed, and the settlement of the superstructure of reinforced pile foundation has been greatly reduced. 


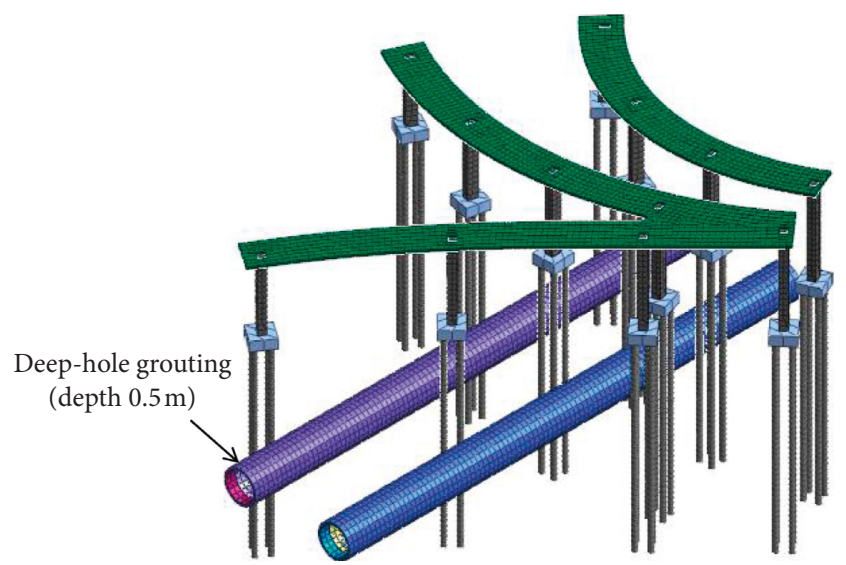

(a)

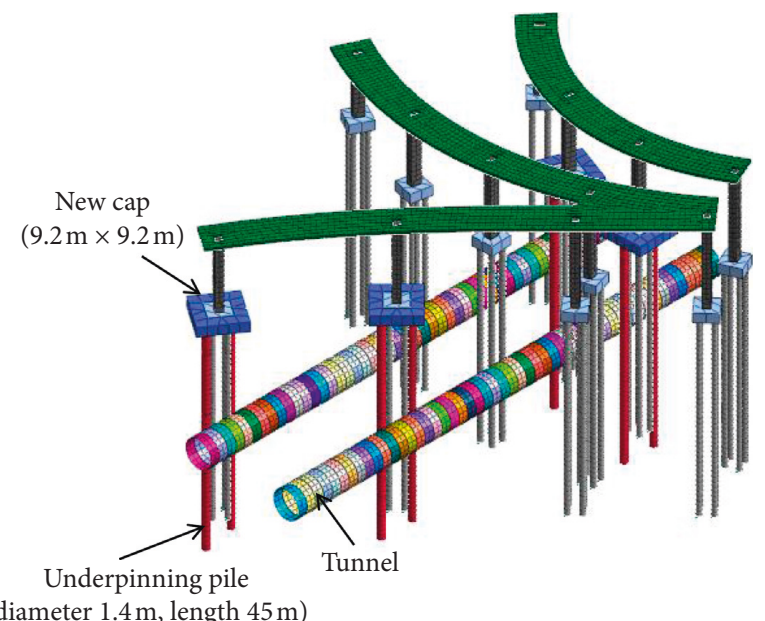

(b)

Figure 11: Three-dimensional finite element model: (a) deep-hole grouting; (b) pile foundation underpinning.

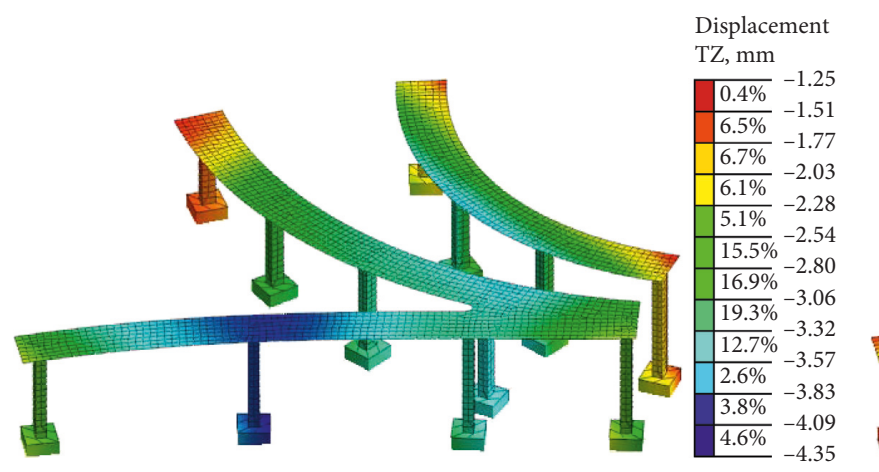

(a)

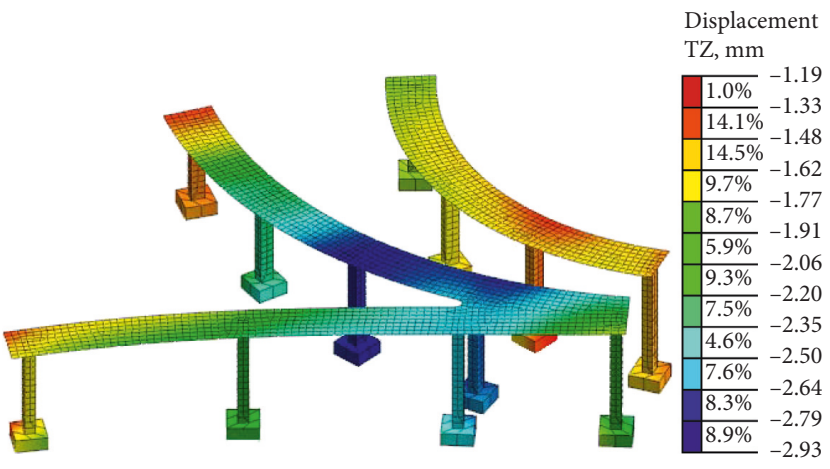

(b)

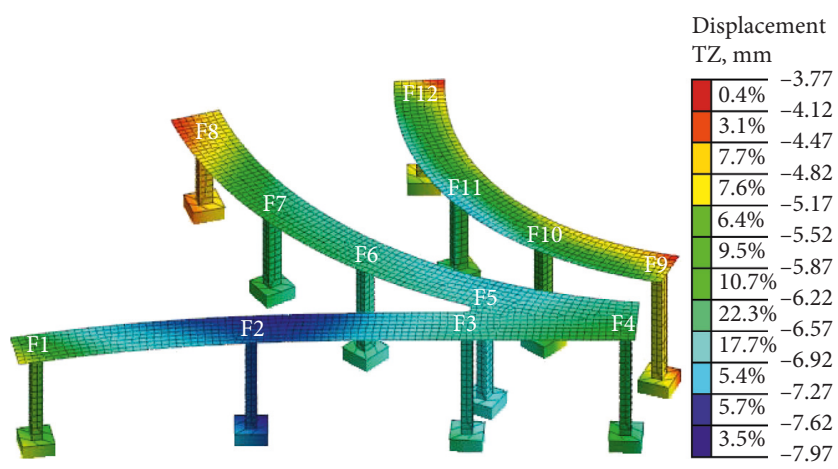

(c)

Figure 12: Calculated settlement of bridge: (a) deep-hole grouting; (b) pile foundation underpinning; (c) without protection. The values (in red characters) represent the percentage of displacement. For an example, the red area in Figure 12 (c) (displacement between $-3.77 \mathrm{~mm}$ and $-4.12 \mathrm{~mm}$ ) accounts for $0.4 \%$ of the total displacement of the bridge.

5.2. Settlement of Ground Surface. Tunnel excavation will cause surface subsidence, thus forming settlement trough, and the presence of pile foundation underneath the surface would alter the trough shape. Figure 13 is obtained from the ground settlement data at the tunnel longitudinal $Y=42$ (affected by F2 pile foundation) and $Y=55 \mathrm{~m}$ (not affected by the pile foundations). From Figure 13(a), the maximum settlement of the ground is exactly where the cap is located, and the settlement of the cap is much larger than that of the ground, which indicates that the tunnel construction has a greater impact on the bridge structure than the soil. The deep-hole grouting scheme greatly reduces the ground settlement, but the settlement at F2 is still relatively large. The pile foundation underpinning scheme not only reduces 


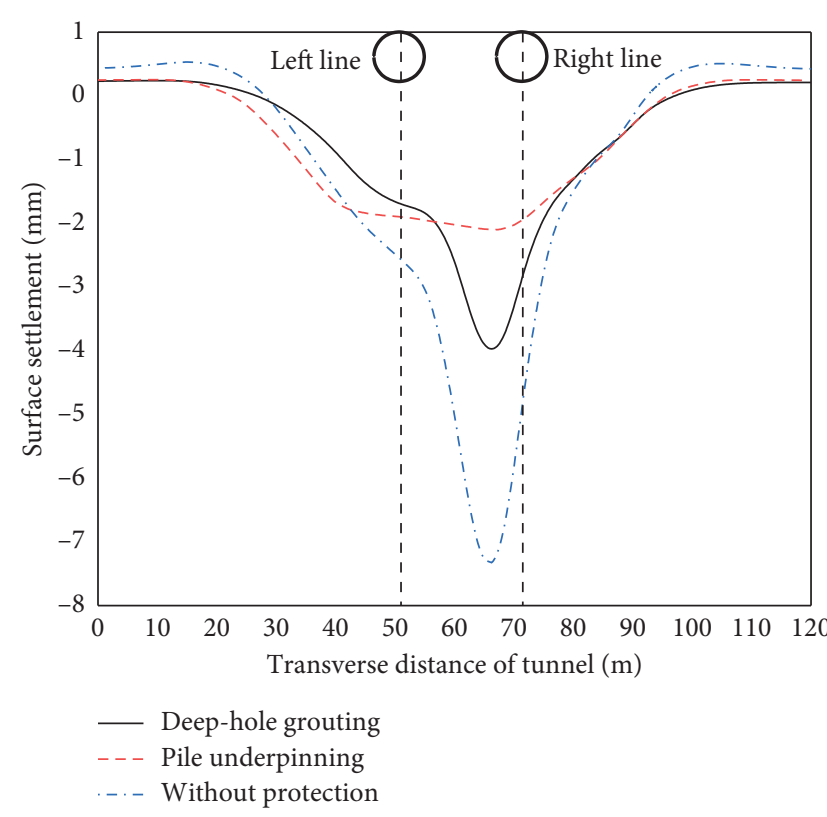

(a)

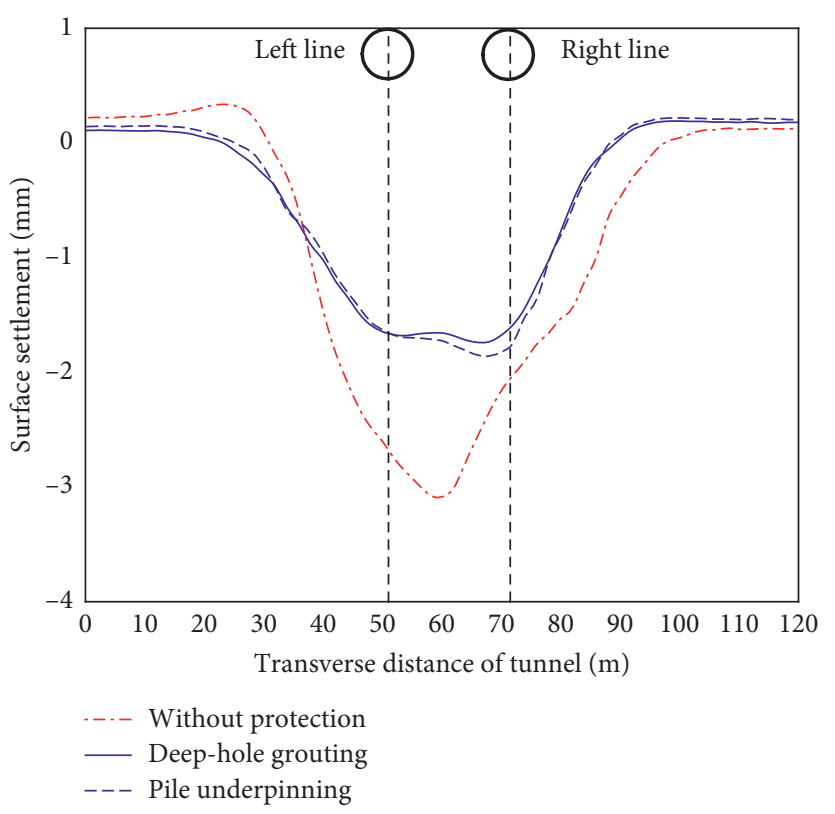

(b)

FIgURE 13: Ground settlement curves of different schemes: (a) $Y=42 \mathrm{~m}$; (b) $Y=54 \mathrm{~m}$.

the influence of pile foundation on soil settlement but also reduces the ground settlement due to the reinforcement of F2. It can be seen from Figure 13(b) that the three settlement curves are symmetrical according to the center line of the two tunnels. When the tunnel is excavated directly, the settlement curve is V-shaped, and the maximum ground settlement reaches about $3.1 \mathrm{~mm}$. In the pile foundation underpinning scheme and deep-hole grouting scheme, it can be found that obvious settlement troughs are formed on the ground surface after tunnel construction. Furthermore, the maximum ground subsidence under the two protective schemes is about $1.8 \mathrm{~mm}$, and their ground settlement curves basically coincide with each other, which shows that the control effect of two schemes on ground settlement is similar, and the effect is both remarkable (reduce about 41.9\%). The measured data of ground surface deformation during shield excavation were obtained in a section of Tianjin Metro [59]. The measured results of surface subsidence are shown in Figure 14, and the final surface subsidence is less than $4 \mathrm{~mm}$. It can be seen that the measured results of the similar project in the same area are basically consistent with the calculated results, which can verify that the calculated results obtained by the finite element method are reliable in this study.

5.3. Lateral Deformation of Piles. The squeezing action of shield tunneling will cause a certain horizontal displacement of the adjacent pile foundation. When the external load continues to be applied on the deformed pile foundation, the pile foundation will be in an unfavorable state of eccentric compression, which is extremely harmful to the pile foundation. Therefore, it is essential to discuss and analyze the lateral deformation of piles as an important parameter. After the completion of shield construction, the horizontal displacement in the direction of tunnel excavation is smaller than that in the direction perpendicular to the tunnel excavation. For this reason, the data of the latter were selected as shown in Figure 15. According to the calculation results, the maximum lateral deformation of pile foundation is about $8.4 \mathrm{~mm}$ without reinforcement. Referring to the Technical Code for Building Pile Foundation (JGJ 94-2008) [60], the lateral deformation of pile foundation of sensitive building should not exceed $6 \mathrm{~mm}$, and the lateral deformation of pile foundation of general building should be less than $10 \mathrm{~mm}$. It means that the lateral deformation of some piles has exceeded the alarm value stipulated in the code, and these piles would be in a dangerous working state. Therefore, it is necessary to take some mitigation measures to protect the piles. The maximum lateral deformation of pile foundation is reduced to $5.1 \mathrm{~mm}$ and $3.1 \mathrm{~mm}$ after pile foundation underpinning and deep-hole grouting, respectively, which are dramatically less than the deformation for piles without protection. Figure 15(d) shows the lateral deformation of the pile foundation only $0.8 \mathrm{~m}$ away from the tunnel. It can be observed that the maximum lateral deformation occurs at a depth of about $20 \mathrm{~m}$, which coincides with the tunnel depth. The lateral deformation of pile foundation is obviously decreased after two protective schemes were adopted. And lateral deformation of the pile after deep-hole grouting is the lowest, which can deduce that the deep-hole grouting scheme can lead to a better mechanical performance of the piles which interact with soil.

5.4. Bending Moment of Piles. In the model, the direction of the unit coordinate system of pile foundation is different from that of the model coordinate system. The $Y$ direction of 


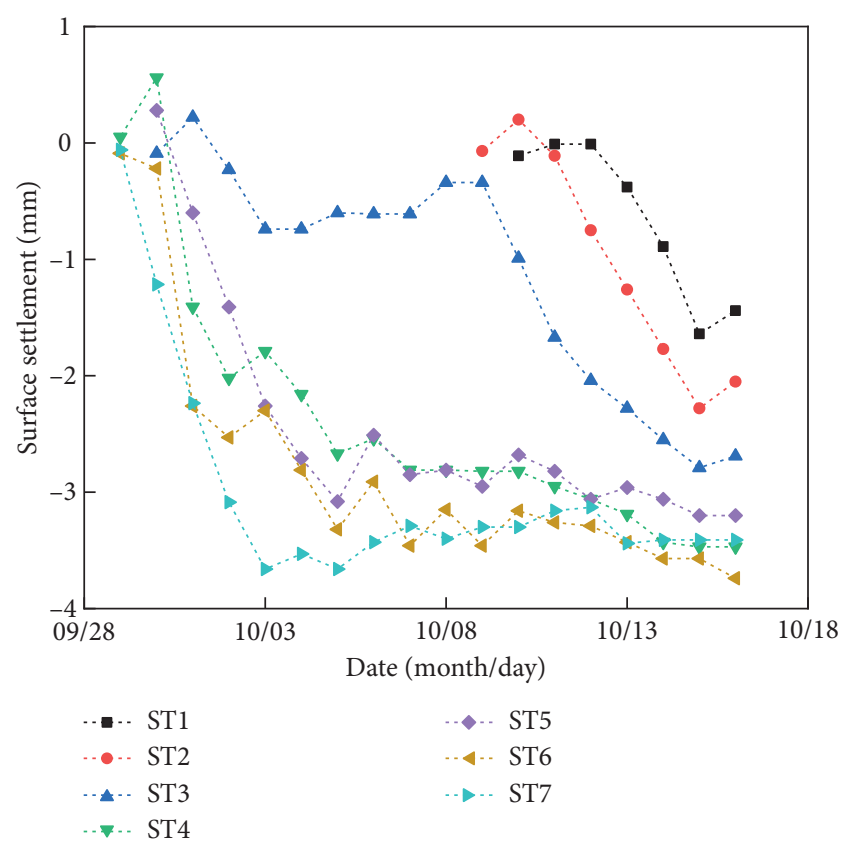

(a)

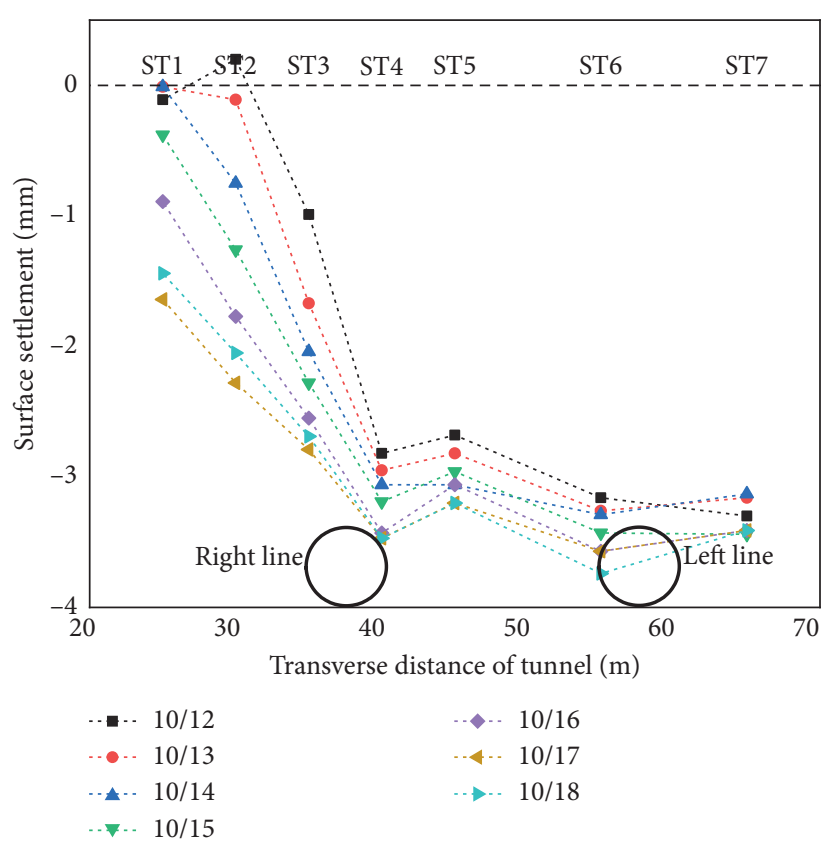

(b)

Figure 14: Measured settlement data: surface settlement at (a) each measuring point and (b) different dates.

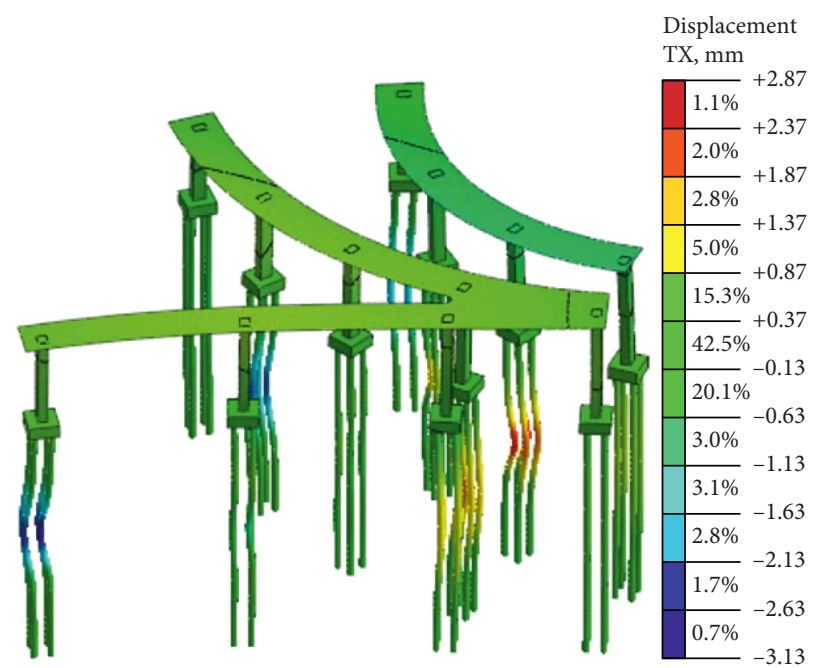

(a)

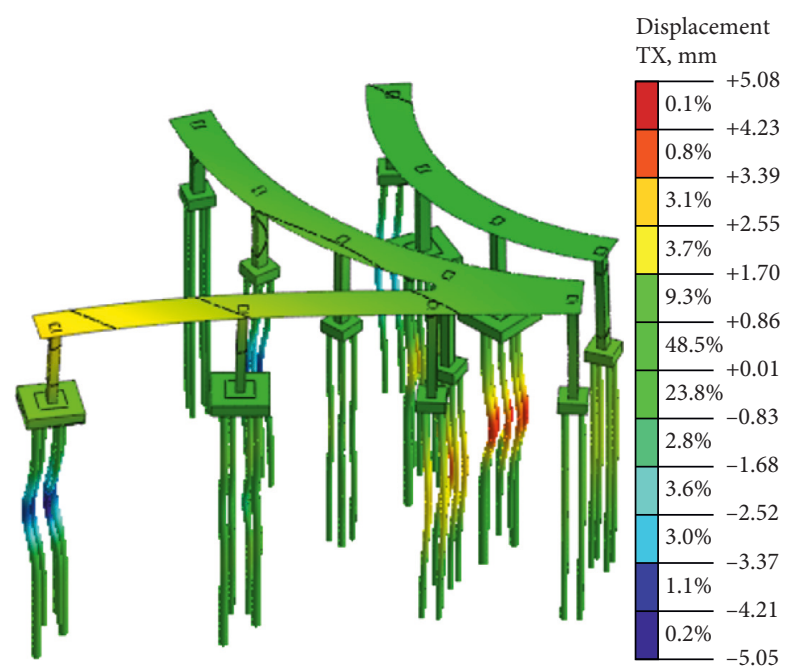

(b)

Figure 15: Continued. 


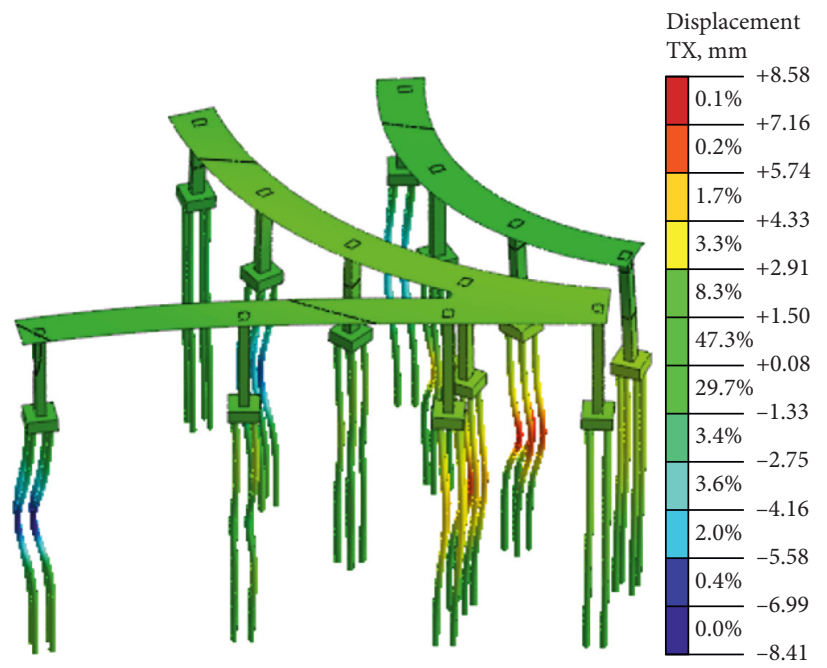

(c)

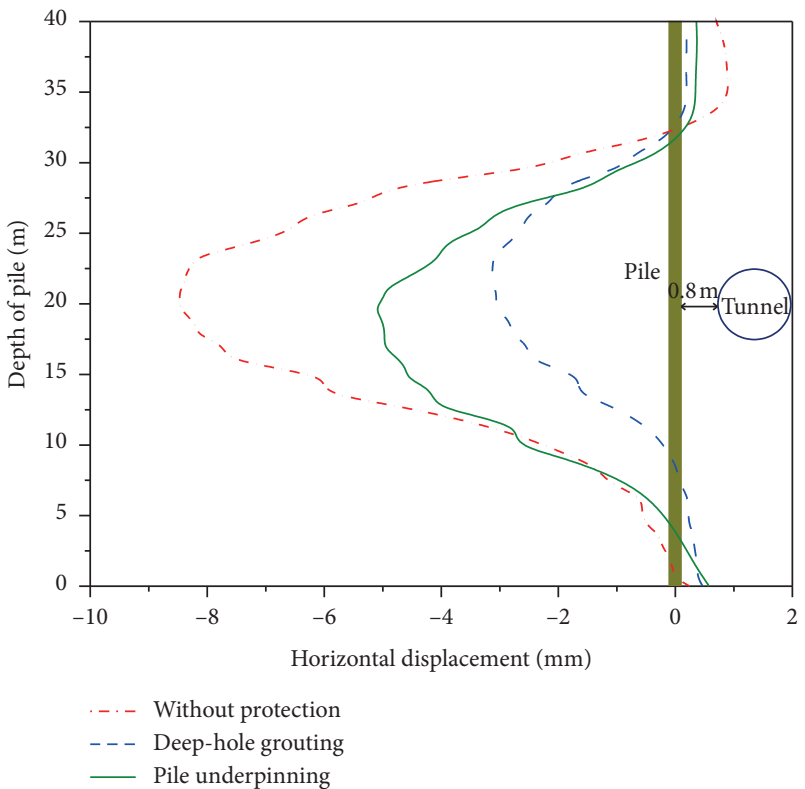

(d)

FIGURE 15: Horizontal displacement of piles: (a) deep-hole grouting; (b) pile foundation underpinning; (c) without protection; (d) horizontal displacement of the nearest pile.

the unit coordinate system of pile foundation is the $X$ direction of the model coordinate system (perpendicular to the direction of tunneling), and the $Z$ direction of the unit coordinate system is the $Y$ direction of the model coordinate system (the direction of tunneling). Figure 16 shows the distribution of bending moment along the piles in three schemes. As it can be observed in Figure 16, the extrusion force produced by shield tunneling does cause a significant increase in the bending moment of piles, especially those near the tunnel. The maximum bending moment appears at the corresponding depth of the tunnel, and the influence range of shield tunneling on the bending moment of the pile body is about one time of the diameter of the tunnel. The results shows that two protective schemes significantly reduced the influence on internal force of piles during the shield tunneling and these two schemes reduce the maximum bending moment of piles by $39.9 \%$ and $34.8 \%$, respectively. After shield tunneling, F1 and F11 pile group foundations are most affected, but in terms of bending moment, they can withstand the corresponding horizontal deformation. By comparing Figures 16(a)-16(c), it is clear that the protective effectiveness of the deep-hole grouting scheme is better than that of pile foundation underpinning during the construction process. In view of this, it is suggested to adopt the deep-hole grouting scheme to protect the pile groups.

5.5. Discussion. By comparing the calculated results of stress and deformation of pile groups under the three working conditions mentioned above, it is found that the pile groups and the superstructure of the bridge have experienced tremendous changes during shield construction. With the adoption of two protective schemes, the stress and deformation of pile groups, bridge structure, and soil all decrease drastically, which shows that the protective effect is obvious. However, there are still some differences between the two schemes. Among them, the deep-hole grouting scheme has better control effect on the lateral deformation and bending moment of the pile body, while the pile foundation underpinning scheme has better effectiveness on reducing the settlement of bridge structure and ground deformation. The disadvantage of the pile underpinning scheme is that the horizontal displacement of piles close to the tunnel is still relatively large after tunneling, and this technology would be limited by the construction site. Pile underpinning construction not only has a long construction period but also affects the traffic on the bridge. Besides, the properties of soft soil may be worse in the actual tunnel site, and the deep-hole grouting scheme can improve the mechanical properties of soil and ensure the stability of tunnel structure during the metro operation. Therefore, based on the comparative analysis of above two schemes, the deephole grouting reinforcement scheme is a better choice.

As this project is still in the stage of design demonstration, there is no comparative analysis between monitoring data and calculated results. But according to the analysis of calculated results and previous measured data, it can be considered that the calculated results in this paper are reliable and can play a guiding role in engineering safety assessment. Due to the limitation of numerical calculation and the assumptions in finite element analysis, it is difficult to make quantitative and accurate prediction of engineering. Therefore, according to the calculation results and engineering experience, more monitoring points should be arranged in sensitive structures, and more attention should be paid to monitoring. Real-time monitoring should be carried out on the deformation of bridge during the shield 


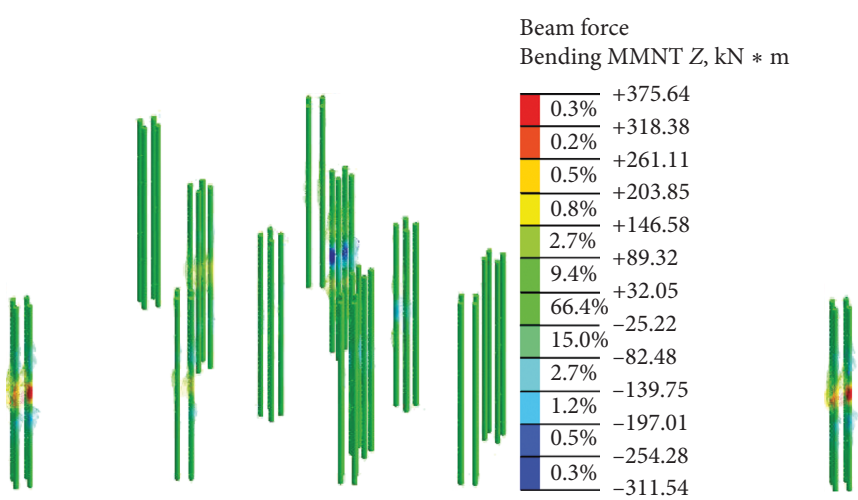

(a)

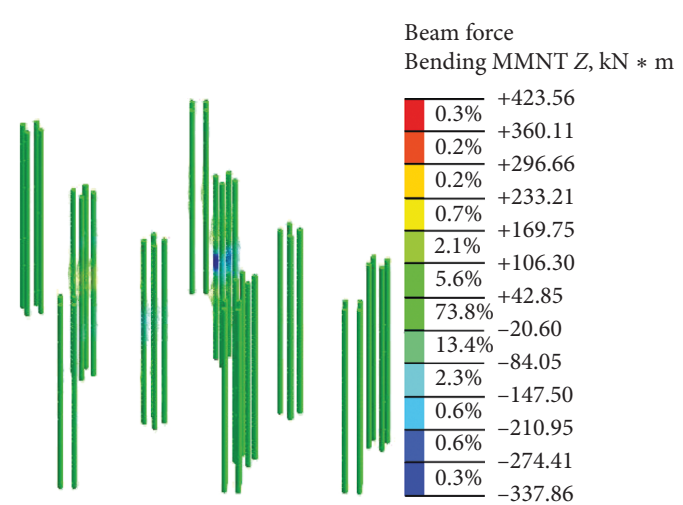

(b)

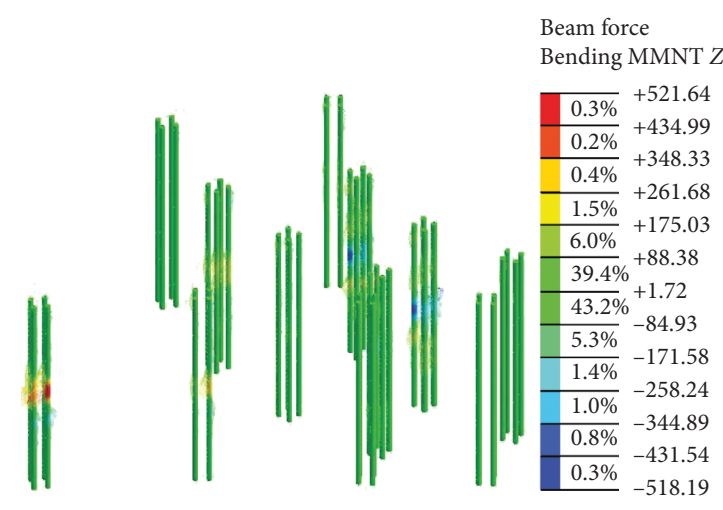

(c)

FIGURE 16: Bending moment of piles: (a) deep-hole grouting; (b) pile foundation underpinning; (c) without protection.

construction. When it is found that the monitoring data exceed the alarm value, it should be warned in time to ensure the smooth advancing of tunnel.

\section{Conclusions}

The engineering construction area studied is located between Lijiang Road station and Tumor Hospital station of Tianjin Metro Line 7. The left and right lines are located in the center of the Shiyou Bridge, and the whole shield tunnel is extremely close to pile groups, the nearest distance is only $0.8 \mathrm{~m}$. Therefore, it is vital to select an appropriate protective scheme to guarantee the safety of bridge structure during the tunneling construction and, subsequently, metro operation. In view of this, through laboratory tests, the main characteristics and mechanical parameters of site soil were determined. A three-dimensional finite element model was carried out to compare and analyze stress and deformation of the bridge after excavation for three cases. The main conclusions are as follows:

(1) In the numerical model, a thickness-free contact element is used to simulate the pile-soil interaction behavior which is controlled by three parameters: normal stiffness modulus $K_{\mathrm{n}}$, tangential stiffness modulus $K_{\mathrm{t}}$, and ultimate shear force. The results show that when the stiffness modulus of the contact element exceeds $10^{5} \mathrm{~Pa} / \mathrm{m}$, the parameters of pile foundation and soil will be less affected with the increase of the stiffness modulus. With the increase of normal pressure, the tangential stiffness modulus rises gradually, and the tangential stiffness modulus of pile foundation in silty clay is between $35.7 \mathrm{MPa}$ and $102 \mathrm{MPa}$. The value of the normal stiffness modulus is 10 times of the tangential stiffness modulus.

(2) The calculation results show that the overall settlement of ground and the superstructure of bridge is large during shield tunneling without the protective scheme, and the horizontal displacement of the adjacent pile foundation exceeds the safety value of the code. Therefore, protective schemes of shield tunneling are carried out from three aspects: disturbance source, transfer medium, and disturbance object.

(3) Comparing various protective schemes, the suitable deep-hole grouting scheme and pile foundation underpinning scheme are selected and analyzed. It is found that the reinforcement effect of the two schemes is obvious: the deformation and stress of pile groups, bridge structure, and soil are obviously controlled, and the shield can smoothly and safely pass through the complex pile groups. The difference between the two schemes is that the deep-hole grouting scheme has better control effect on the lateral deformation and bending moment of pile group foundations, while the pile foundation 
underpinning scheme has better effectiveness on reducing the settlement of bridge structure and ground deformation. Considering that pile foundation underpinning requires a long construction period and the construction process will affect traffic on the bridge, the deep-hole grouting reinforcement scheme is suggested to protect pile groups in this project. Although this study cannot reveal the perfect working mechanism of the reinforcement measures due to the limits of the numerical model, such conclusions can show the basic principles of designing a similar protective scheme.

\section{Data Availability}

The data used to support the findings of this study are available from the corresponding author upon request.

\section{Conflicts of Interest}

The authors declare that they have no conflicts of interest.

\section{Acknowledgments}

This work was financially supported by the National Natural Science Foundation of China (Grant No. 51978066), the Project on Social Development of Shaanxi Provincial Science and Technology Department (No. 2018SF-382), the Special Fund for Basic Scientific Research of Central Colleges of Chang'an University (Nos. 310821172004, 310821153312, and 310821165011).

\section{References}

[1] R. B. Peck, "Deep excavation and tunneling in soft ground, State of the art report," in Proceedings of 7th International Conference on Soil Mechanics and Foundation Engineering, pp. 225-290, Mexico City, Mexico, 1969.

[2] P. B. Attewell and I. W. Farmer, "Ground disturbance caused by shield tunnelling in a stiff, overconsolidated clay," Engineering Geology, vol. 8, no. 4, pp. 361-381, 1974.

[3] K.-H. Park, "Analytical solution for tunnelling-induced ground movement in clays," Tunnelling and Underground Space Technology, vol. 20, no. 3, pp. 249-261, 2005.

[4] S. G. Ercelebi, H. Copur, and I. Ocak, "Surface settlement predictions for Istanbul Metro tunnels excavated by EPBTBM," Environmental Earth Sciences, vol. 62, no. 2, pp. 357-365, 2011.

[5] P. F. Li, H. H. Zou, F. Wang, and H. C. Xiong, "An analytical mechanism of limit support pressure on cutting face for deep tunnels in the sand," Computers and Geotechnics, vol. 119, Article ID 103372, 2020.

[6] W. Cheng, G. Li, N. Liu, J. Xu, and S. Horpibulsuk, "Recent massive incidents for subway construction in soft alluvial deposits of Taiwan: a review," Tunnelling and Underground Space Technology, vol. 96, Article ID 103178, 2020.

[7] Z. Zhang and F. Sun, "Thermal-mechanical coupled analysis for tunnel lining with circular openings," Tunnelling and Underground Space Technology, vol. 98, Article ID 103192, 2020.
[8] L. T. Chen, H. G. Poulos, and N. Loganathan, "Pile responses caused by tunneling," Journal of Geotechnical and Geoenvironmental Engineering, vol. 125, no. 3, pp. 207-215, 1999.

[9] H. Mroueh and I. Shahrour, "Three-dimensional finite element analysis of the interaction between tunneling and pile foundations," International Journal for Numerical and Analytical Methods in Geomechanics, vol. 26, no. 3, pp. 217-230, 2002.

[10] C. Y. Cheng, G. R. Dasari, C. F. Leung, Y. K. Chow, and H. B. Rosser, "3D numerical study of tunnel-soil-pile interaction," Tunnelling and Underground Space Technology, vol. 19, no. 4, pp. 381-382, 2004.

[11] G. T. K. Lee and C. W. W. Ng, "Effects of advancing open face tunneling on an existing loaded pile," Journal of Geotechnical and Geoenvironmental Engineering, vol. 131, no. 2, pp. 193201, 2005.

[12] C. J. Lee and S. W. Jacobsz, "The influence of tunnelling on adjacent piled foundations," Tunnelling and Underground Space Technology, vol. 21, no. 3-4, p. 430, 2006.

[13] C. Liu, Z. Zhang, and R. A. Regueiro, "Pile and pile group response to tunnelling using a large diameter slurry shield-case study in Shanghai," Computers and Geotechnics, vol. 59, pp. 21-43, 2014.

[14] D. S. Liyanapathirana and R. Nishanthan, "Influence of deep excavation induced ground movements on adjacent piles," Tunnelling and Underground Space Technology, vol. 52, pp. 168-181, 2016.

[15] J. Wang, W. Li, and Z. Song, "Development and implementation of new triangular finite element based on MGE theory for bi-material analysis," Results in Physics, vol. 13, Article ID 102231, 2019.

[16] Z.-F. Wang, S.-L. Shen, and G. Modoni, "Enhancing discharge of spoil to mitigate disturbance induced by horizontal jet grouting in clayey soil: theoretical model and application," Computers and Geotechnics, vol. 111, pp. 222-228, 2019.

[17] H. G. Poulos, D. P. Stewart, and N. Loganathan, "Centrifuge model testing of tunnelling-induced ground and pile deformations," Géotechnique, vol. 50, no. 3, pp. 283-294, 2000.

[18] S. W. Jacobsz, J. R. Standing, R. J. Mair, T. Hagiwara, and T. Sugiyama, "Centrifuge modelling of tunnelling near driven piles," Soils and Foundations, vol. 44, no. 1, pp. 49-56, 2004.

[19] K.-H. Chiang and C.-J. Lee, "Responses of single piles to tunneling-induced soil movements in sandy ground," $\mathrm{Ca}$ nadian Geotechnical Journal, vol. 44, no. 10, pp. 1224-1241, 2007.

[20] C. W. W. Ng, H. Lu, and S. Y. Peng, "Three-dimensional centrifuge modelling of the effects of twin tunnelling on an existing pile," Tunnelling and Underground Space Technology, vol. 35, pp. 189-199, 2013.

[21] Y. Hong, M. A. Soomro, and C. W. W. Ng, "Settlement and load transfer mechanism of pile group due to side-by-side twin tunnelling," Computers and Geotechnics, vol. 64, pp. 105-119, 2015.

[22] Y. Zheng, J. Xiong, T. Liu, X. Yue, and J. Qiu, "Performance of a deep excavation in Lanzhou strong permeable sandy gravel strata," Arabian Journal of Geosciences, vol. 13, no. 16, 12 pages, 2020.

[23] D. T. Niu, L. Zhang, F. Qiang, B. Wen, and D. M. Luo, "Critical conditions and life prediction of reinforcement corrosion in coral aggregate concrete," Construction and Building Materials, vol. 238, Article ID 117685, 2020.

[24] R. G. Lee, A. J. Turner, and L. J. Whitworth, "Deformations caused by tunneling beneath a piled structure," Proceedings of the international conference on soil mechanics and 
foundation engineering-international society for soil mechanics and foundation engineering," Aa Balkema, vol. 3, pp. 873-878, 1994.

[25] R. J. Mair, R. N. Taylor, and J. B. Burland, "Prediction of ground movements and assessment of risk of building damage due to bored tunnelling," in Proceedings of the International Symposium on Geotechnical Aspects of Underground Construction in Soft Ground, pp. 713-718, Balkema, London, UK, April 1996.

[26] D. R. Coutts and J. Wang, "Monitoring of reinforced concrete piles under horizontal and vertical loads due to tunneling," in Proceedings of the International conference on tunnels and underground structures, pp. 514-546, Balkema, Singapore, 2000.

[27] D. Selemetas, J. R. Standing, and R. J. Mair, "The response of full-scale piles to tunnelling," in Proceedings of the 5th International Symposium on Geotechnical Aspects of Underground Construction in Soft Ground, pp. 763-769, Taylor \& Francis, Amsterdam, the Netherlands, June 2005.

[28] A. Sirivachiraporn and N. Phienwej, "Ground movements in EPB shield tunneling of Bangkok subway project and impacts on adjacent buildings," Tunnelling and Underground Space Technology, vol. 30, pp. 10-24, 2012.

[29] T. Boonyarak, K. Phisitkul, C. W. W. Ng, W. Teparaksa, and Z. Z. Aye, "Observed ground and pile group responses due to tunneling in Bangkok stiff clay," Canadian Geotechnical Journal, vol. 51, no. 5, pp. 479-495, 2014.

[30] X. L. Wang, J. X. Lai, J. L. Qiu, W. Xu, L. X. Wang, and Y. B. Luo, "Geohazards, reflection and challenges in mountain tunnel construction of China: a data collection from 2002 to 2018," Geomatics, Natural Hazards and Risk, vol. 11, no. 1, pp. 667-675, 2020.

[31] X. Liu, Q. Fang, D. Zhang, and Y. Liu, "Energy-based prediction of volume loss ratio and plastic zone dimension of shallow tunnelling," Computers and Geotechnics, vol. 118, Article ID 103343, 2020.

[32] Y. Wei, W. Guo, and Q. Zhang, "A model for predicting evaporation from fresh concrete surface during the plastic stage," Drying Technology, vol. 37, no. 11, 2019.

[33] T. Liu, Y. Zhong, Z. Feng, W. Xu, and F. Song, "New construction technology of a shallow tunnel in boulder-cobble mixed grounds," Advances in Civil Engineering, vol. 2020, Article ID 5686042, 14 pages, 2020.

[34] P. Li, K. Chen, F. Wang, and Z. Li, “An upper-bound analytical model of blow-out for a shallow tunnel in sand considering the partial failure within the face," Tunnelling and Underground Space Technology, vol. 91, pp. 1-12, 2019.

[35] H. Sun, Q. Wang, P. Zhang, Y. Zhong, and X. Yue, "Spatialtemporal characteristics of tunnel traffic accidents in China from 2001 to present," Advances in Civil Engineering, vol. 2019, Article ID 4536414, 12 pages, 2019.

[36] X. Liu, Q. Fang, D. Zhang, and Z. Wang, "Behaviour of existing tunnel due to new tunnel construction below," Computers and Geotechnics, vol. 110, pp. 71-81, 2019.

[37] W.-C. Cheng, Z.-P. Song, W. Tian, and Z.-F. Wang, "Shield tunnel uplift and deformation characterisation: a case study from Zhengzhou metro," Tunnelling and Underground Space Technology, vol. 79, pp. 83-95, 2018.

[38] D. I. Harris, R. J. Mair, J. P. Love, R. N. Taylor, and T. O. Henderson, "Observations of ground and structure movements for compensation grouting during tunnel construction at Waterloo station," Géotechnique, vol. 44, no. 4, pp. 691-713, 1994.
[39] K. Takahashi, N. Fukazawa, T. Hagiwara, and M. Hosoda, "Observational control of slurry shield tunnels with super close spacing under the nearby bridge abutments loads," Tunneling and Underground Space Technology, vol. 19, no. 4-5, p. 390, 2004.

[40] Y. Xiang, Z. Jiang, and H. He, “Assessment and control of metro-construction induced settlement of a pile-supported urban overpass," Tunnelling and Underground Space Technology, vol. 23, no. 3, pp. 300-307, 2008.

[41] A. Kirsch and L. Piazzi, "Numerical investigation of the effectiveness of a bored pile wall for the minimisation of settlement resulting from tunnel driving," Geomechanik und Tunnelbau, vol. 2, no. 6, pp. 753-765, 2010.

[42] E. Bilotta and G. Russo, "Use of a line of piles to prevent damages induced by tunnel excavation," Journal of Geotechnical and Geoenvironmental Engineering, vol. 137, no. 3, pp. 254-262, 2011.

[43] Y. Bai, Z. Yang, and Z. Jiang, "Key protection techniques adopted and analysis of influence on adjacent buildings due to the Bund Tunnel construction," Tunnelling and Underground Space Technology, vol. 41, pp. 24-34, 2014.

[44] K. Wu, Z. Shao, C. Li, and S. Qin, "Theoretical investigation to the effect of bolt reinforcement on tunnel viscoelastic behavior," Arabian Journal for Science and Engineering, vol. 45, no. 6, pp. 152-163, 2019.

[45] J. Fu, J. Yang, S. Zhu, and Y. Shi, "Performance of jet-grouted partition walls in mitigating the effects of shield-tunnel construction on adjacent piled structures," Journal of Performance of Constructed Facilities, vol. 31, no. 2, 2017.

[46] Z. Wang, K.-W. Zhang, G. Wei, B. Li, Q. Li, and W.-J. Yao, "Field measurement analysis of the influence of double shield tunnel construction on reinforced bridge," Tunnelling and Underground Space Technology, vol. 81, pp. 252-264, 2018.

[47] X. Yu, G. Xing, and Z. Chang, "Flexural behavior of reinforced concrete beams strengthened with near-surface mounted 7075 aluminum alloys bars," Journal of Building Engineering, vol. 28, Article ID 101086, 2020.

[48] Z. Wang, Y. Xie, H. Liu, and Z. Feng, "Analysis on deformation and structural safety of a novel concrete-filled steel tube support system in loess tunnel," European Journal of Environmental and Civil Engineering, vol. 23, no. 3, pp. 1-21, 2019.

[49] X. Wang, S. He, J. Lai, and R. Garnes, "Karst geology and mitigation measures for hazards during metro system construction in Wuhan, China," Natural Hazards, vol. 101, no. 3, pp. 1909-1935, 2020.

[50] Y. Zhang, D. Zhang, Q. Fang, L. Xiong, L. Yu, and M. Zhou, "Analytical solutions of non-Darcy seepage of grouted subsea tunnels," Tunnelling and Underground Space Technology, vol. 96, Article ID 103182, 2020.

[51] B. L. Zhu, Computational Soil Mechanics, Shanghai Science and Technology Press, Shanghai, China, 1990, in Chinese.

[52] B. C. Dong, Study on Contact Elements and Related Parameters in Geotechnical Engineering Simulation, Huazhong University of Science and Technology, Wuhan, China, 2005, in Chinese.

[53] Z. X. Zhang, C. Liu, X. Huang, C. Y. Kwok, and L. Teng, "Three-dimensional finite-element analysis on ground responses during twin-tunnel construction using the URUP method," Tunnelling and Underground Space Technology, vol. 58, pp. 133-146, 2016.

[54] P. Jongpradist, T. Kaewsri, A. Sawatparnich et al., "Development of tunneling influence zones for adjacent pile 
foundations by numerical analyses," Tunnelling and Underground Space Technology, vol. 34, pp. 96-109, 2013.

[55] X. Li, C. Qi, and P. Zhang, "A micro-macro confined compressive fatigue creep failure model in brittle solids," International Journal of Fatigue, vol. 130, Article ID 105278, 14 pages, 2020.

[56] Y. Y. Li, Y. M. Sun, J. L. Qiu, T. Liu, L. Yang, and H. D. She, "Moisture absorption characteristics and thermal insulation performance of thermal insulation materials for cold region tunnels," Construction and Building Materials, vol. 237, Article ID 117765, 15 pages, 2020.

[57] K. Wu, Z. Shao, S. Qin, and B. Li, "Determination of deformation mechanism and countermeasures in silty clay tunnel," Journal of Performance of Constructed Facilities, vol. 34, no. 1, Article ID 04019095, 2020.

[58] Z. Song, J. Mao, X. Tian, Y. Zhang, and J. Wang, "Optimization analysis of controlled blasting for passing through houses at close range in super-large section tunnels," Shock and Vibration, vol. 2019, Article ID 1941436, 16 pages, 2019.

[59] P. Lu, H. Jiang, and G. Zheng, "Impact on existing tunnel due to construction of new shield tunnel in close proxomity," Journal of Beijing University of Technology, vol. 40, no. 8, pp. 1121-1127, 2014, in Chinese.

[60] Ministry of Housing and Urban-Rural Construction of the People's Republic of China, "Technical specification for building pile foundation," Geotechnical Mechanics, 2008, in Chinese. 


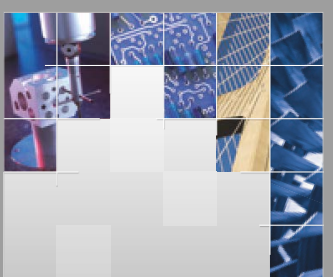

\section{Enfincering}
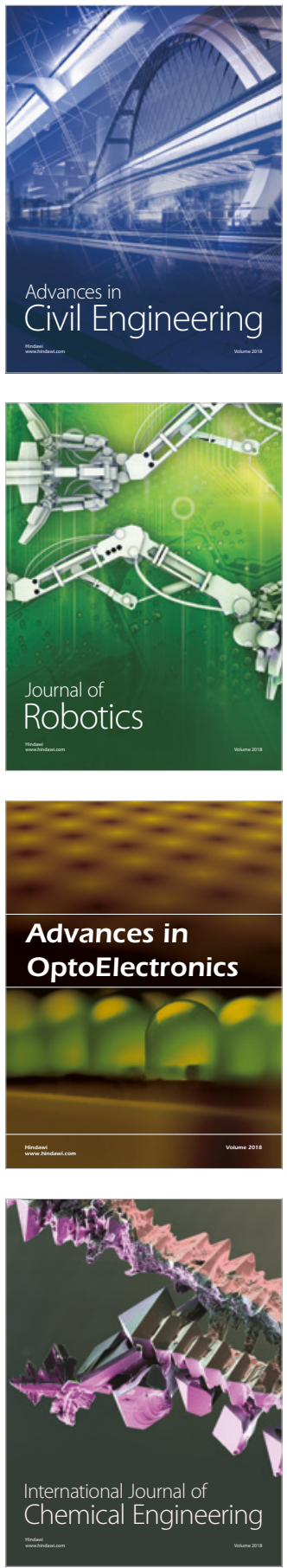

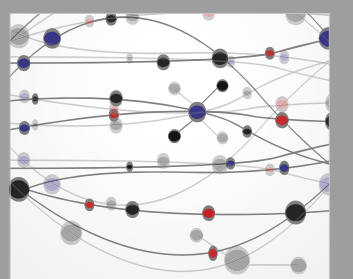

\section{Rotating \\ Machinery}

The Scientific World Journal

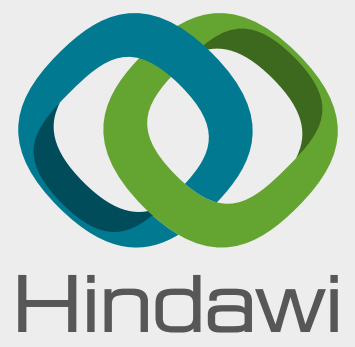

Submit your manuscripts at

www.hindawi.com
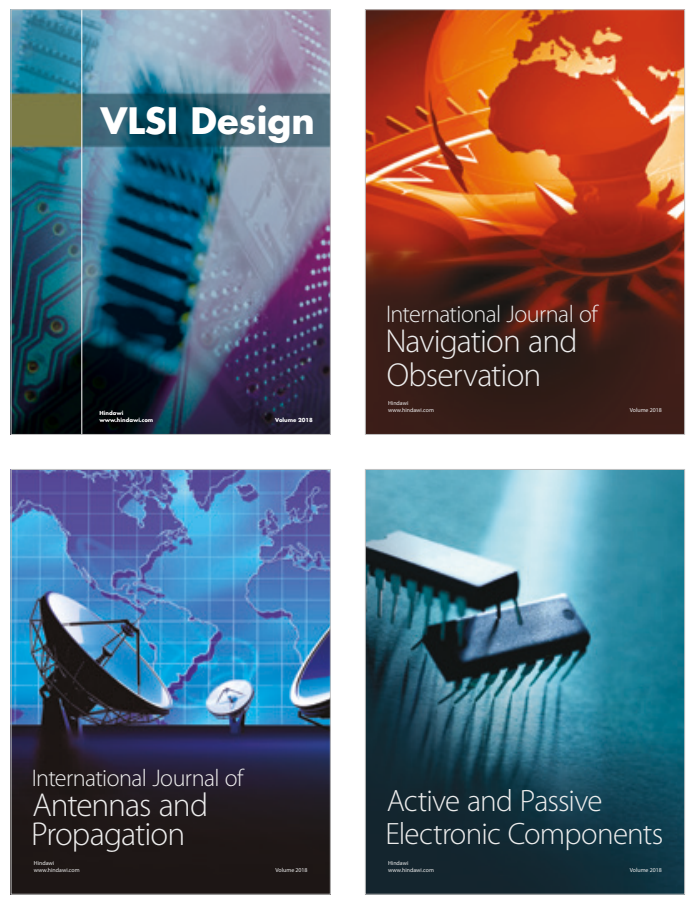
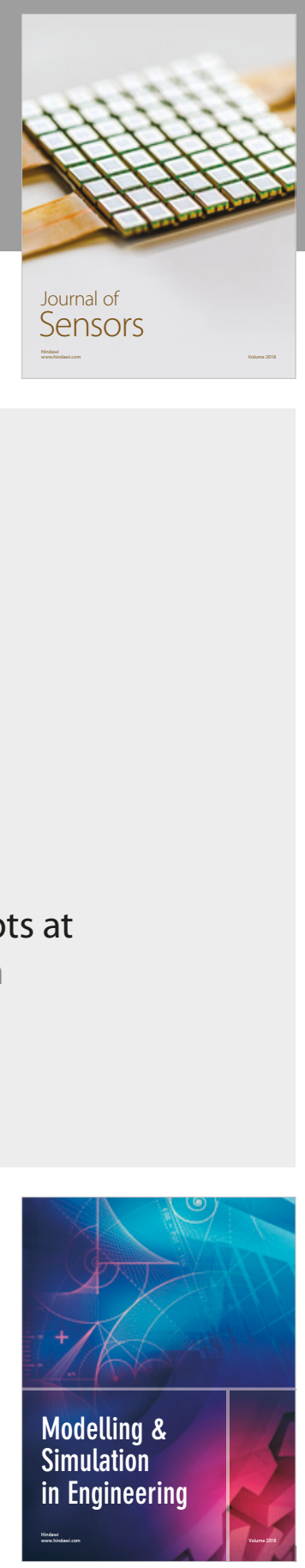

\section{Advances \\ Multimedia}
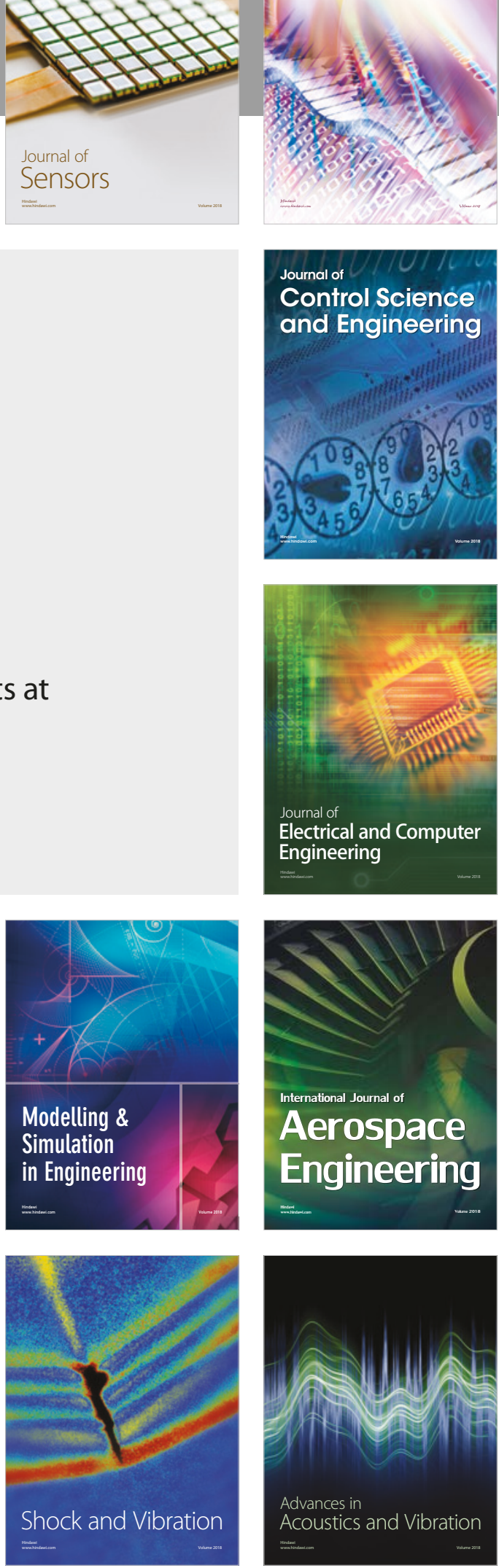